\title{
Streamlining Transportation Corridor Planning Processes: Freight and Traffic Information
}

\section{December 2009}

\section{Prepared by}

Oscar Franzese, Ph.D.

Senior Researcher, ORNL 


\section{DOCUMENT AVAILABILITY}

Reports produced after January 1, 1996, are generally available free via the U.S. Department of Energy (DOE) Information Bridge.

Web site http://www.osti.gov/bridge

Reports produced before January 1, 1996, may be purchased by members of the public from the following source.

National Technical Information Service
5285 Port Royal Road
Springfield, VA 22161
Telephone 703-605-6000 (1-800-553-6847)
TDD 703-487-4639
Fax 703-605-6900
E-mail info@ntis.gov
Web site http://www.ntis.gov/support/ordernowabout.htm

Reports are available to DOE employees, DOE contractors, Energy Technology Data Exchange (ETDE) representatives, and International Nuclear Information System (INIS) representatives from the following source.

Office of Scientific and Technical Information

P.O. Box 62

Oak Ridge, TN 37831

Telephone 865-576-8401

Fax 865-576-5728

E-mail reports@osti.gov

Web site http://www.osti.gov/contact.html

This report was prepared as an account of work sponsored by an agency of the United States Government. Neither the United States Government nor any agency thereof, nor any of their employees, makes any warranty, express or implied, or assumes any legal liability or responsibility for the accuracy, completeness, or usefulness of any information, apparatus, product, or process disclosed, or represents that its use would not infringe privately owned rights. Reference herein to any specific commercial product, process, or service by trade name, trademark, manufacturer, or otherwise, does not necessarily constitute or imply its endorsement, recommendation, or favoring by the United States Government or any agency thereof. The views and opinions of authors expressed herein do not necessarily state or reflect those of the United States Government or any agency thereof. 
National Consortium for Remote Sensing in Transportation

\title{
Streamlining Transportation Corridor Planning Processes: \\ Freight and Traffic Information
}

\author{
Author \\ Oscar Franzese, ORNL
}

Date Published: December 2009

Prepared by

OAK RIDGE NATIONAL LABORATORY

Oak Ridge, Tennessee 37831-6283

managed by

UT-BATTELLE, LLC

for the

U.S. DEPARTMENT OF ENERGY

under contract DE-AC05-00OR22725 
This page intentionally left blank. 


\section{CONTENTS}

Page

CONTENTS

iii

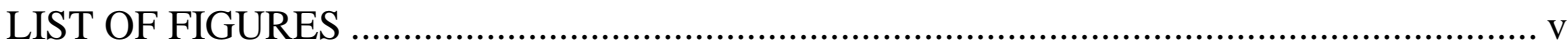

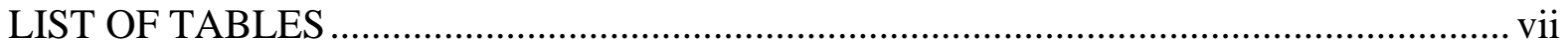

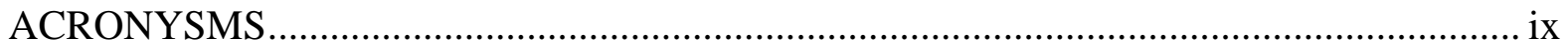

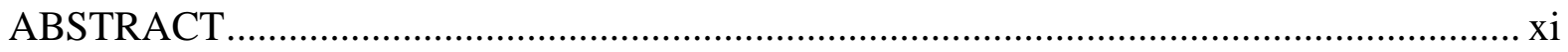

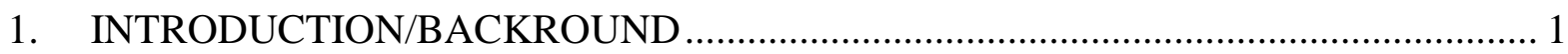

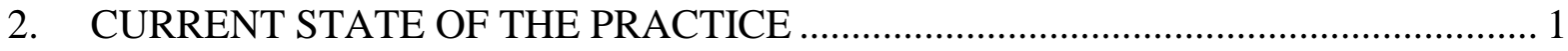

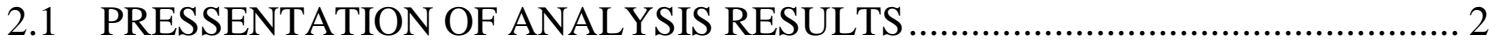

2.2 RESULT PRESENTATION SHORTCOMINGS .............................................. 4

3. PROPOSED APPROACH............................................................................... 7

3.1 INTEGRATION OF TRAVEL DEMAND MODELS AND CRS\&SI

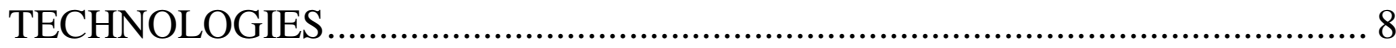

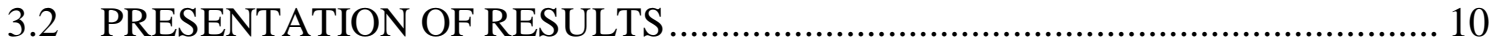

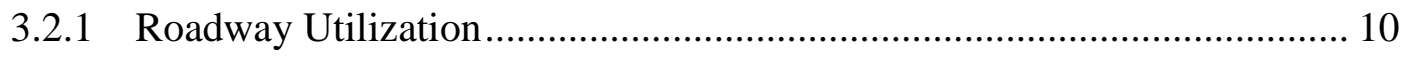

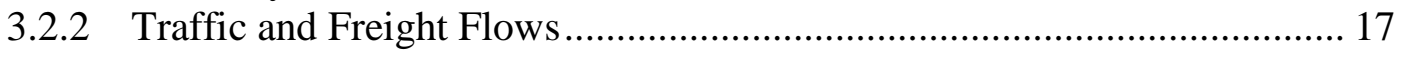

4. BENEFITS OF THE PROPOSED APPROACH ................................................ 24

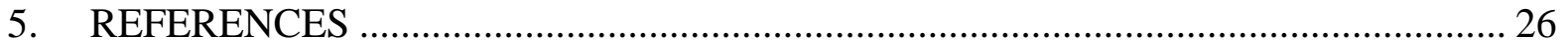


This page intentionally left blank. 


\section{LIST OF FIGURES}

Figure $\quad$ Page

Figure 1 Proposed I-69 and No-Build Alternatives - Traffic Analysis Results (LOS) ........... 3

Figure 2 Proposed I-69 - Traffic Analysis Results (Predicted Traffic Volumes at I-69

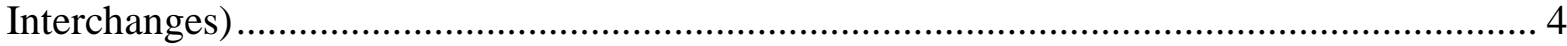

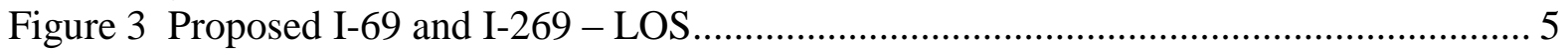

Figure 4 No-Build Alternative I-69 and I-269 - LOS ................................................ 6

Figure 5 No-Build Alternative - Truck Annual Average Daily Traffic (AADT Forecast

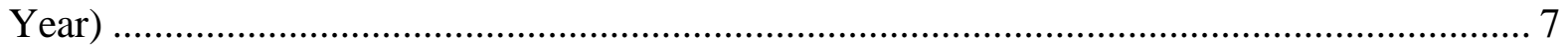

Figure 6 Proposed I-69 and I-269 -LOS for the Entire Highway System (Forecast Year)... 12

Figure 7 No-Build Alternative - LOS for the Entire Highway System (Forecast Year)...... 12

Figure 8 No-Build Alternative - Volume-to-Capacity Ratio (Base Year) ........................... 13

Figure 9 No-Build Alternative - Volume-to-Capacity Ratio (Forecast Year) ...................... 14

Figure 10 Existing System - Delays (Base Year)........................................................ 15

Figure 11 No-Build Alternative - Delays (Forecast Year) ............................................. 15

Figure 12 Existing System - Downtown and Airport Area Delays (Base Year)................. 16

Figure 13 No-Build Alternative - Downtown and Airport Area Delays (Forecast Year).... 16

Figure 14 No-Build Alternative - Freight Volume Change (Base to Forecast Year) ........... 19

Figure 15 No-Build Alternative - Freight Volume / Capacity Change (Base to Forecast

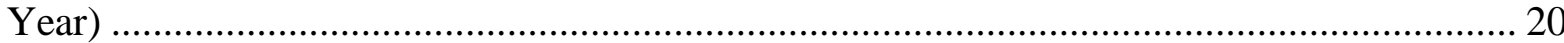

Figure 16 No-Build Alternative - Downtown and Airport Area Freight Volume / Capacity

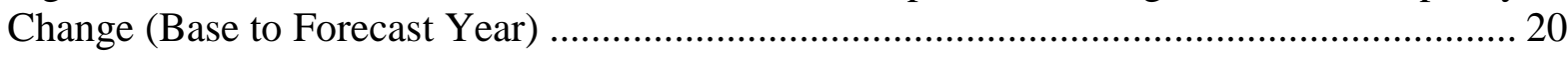

Figure 17 Synthetic O-D Network ........................................................................... 22

Figure 18 Synthetic O-D Network - Existing System.................................................... 23 
This page intentionally left blank. 


\section{LIST OF TABLES}

Table

Page

Table 1 - Variables Contained in the FAF Database File (FAFDATA.DBF)

18

Table 2 - Freight O-D Matrix (Through Traffic).

24 
This page intentionally left blank. 


\section{ACRONYSMS}

AADT: Annual Average Daily Traffic

ADT: Average Daily Traffic

CRS\&SI: Commercial Remote Sensing and Spatial Information

CTA: Center for Transportation Analysis

DOT Department of Transportation

EB: Eastbound

EIS: Environmental Impact Statement

EMME: Equilibre Multimodal/Multimodal Equilibrium

ESRI: Environmental Systems Research Institute, Inc.

FHWA: Federal Highway Administration

GeoPDF: Geodetic Portable Document File

GIS: Geographic Information Systems

GPS: Global Positioning System

GT: Ground Truth

ITS: Intelligent Transportation Systems

LOS: Level of Service

LRTP: (Memphis Area) Long Range Transportation Plan

MDOT: Mississippi Department of Transportation

MinUTP: Minicomputer Urban Transportation Planning software

MPO: Metropolitan Planning Commission

MSU: Mississippi State University

MTRC: Mississippi Transportation Research Center

NB: Northbound

NTRC: National Transportation Research Center

ORNL: Oak Ridge National Laboratory

P: Prototype

R\&D: Research and Development

SB: Southbound

SUI: Section of Independent Utility

TDOT: Tennessee Department of Transportation

US DOT US Department of Transportation

V/C: Volume-to-Capacity Ratio

WB: Westbound 
This page intentionally left blank. 


\begin{abstract}
The traffic investigation is one of the most important parts of an Environmental Impact Statement of projects involving the construction of new roadway facilities and/or the improvement of existing ones. The focus of the traffic analysis is on the determination of anticipated traffic flow characteristics of the proposed project, by the application of analytical methods that can be grouped under the umbrella of capacity analysis methodologies. In general, the main traffic parameter used in EISs to describe the quality of traffic flow is the Level of Service (LOS).

The current state of the practice in terms of the traffic investigations for EISs has two main shortcomings. The first one is related to the information that is necessary to conduct the traffic analysis, and specifically to the lack of integration among the different transportation models and the sources of information that, in general, reside in GIS databases. A discussion of the benefits of integrating Commercial Remote Sensing and Spatial Information (CRS\&SI) technologies and the transportation models used in the EIS traffic investigation is included.

The second shortcoming is in the presentation of the results, both in terms of the appearance and formatting, as well as content. The presentation of traffic results (current and proposed) is discussed. This chapter also addresses the need of additional data, in terms of content and coverage. Regarding the former, other traffic parameters (e.g., delays) that are more meaningful to non-transportation experts than LOS, as well as additional information (e.g., freight flows) that can impact traffic conditions and safety are discussed.

Spatial information technologies can decrease the negative effects of, and even eliminate, these shortcomings by making the relevant information that is input to the models more complete and readily available, and by providing the means to communicate the results in a more clear and efficient manner. The benefits that the application and use of CRS\&SI technologies can provide to help improve and expedite the traffic investigation part of the EIS process are presented.
\end{abstract}


This page intentionally left blank. 


\section{INTRODUCTION/BACKROUND}

The traffic investigation is one of the most important parts of an Environmental Impact Statement (EIS) of projects involving the construction of new roadway facilities and/or the improvement of existing ones. The main focus of the traffic investigation is on the determination of anticipated traffic flow characteristics of the proposed project. These forecasted traffic flows are then compared to the capacity of the corresponding roadway segments of the proposed project to estimate how they will operate in terms of traffic congestion.

This chapter describes the current state of the practice in terms of the traffic information included in EISs, focusing on the models used to conduct the capacity analyses that are typically part of the traffic investigation, and on the presentation of the results of these analyses. Remote sensing and geospatial technologies can expedite and improve this process by making the relevant information that is input to the models more complete and readily available; and by providing the means to communicate the results in a more clear and efficient manner. In order to demonstrate these capabilities, this chapter focuses on the conceptualization of a comprehensive approach for the use of Commercial Remote Sensing and Spatial Information (CRS\&SI) technologies for the characterization of transportation networks for environmental assessments. The chapter also discusses the benefits that the meaningful application of these CRS\&SI technologies provide to understanding the nature of the current and future conditions of the transportation system being studied. An analytical transportation network, which includes regular traffic and freight flows for the selected transportation corridor (I-69 SIU 9) is also developed and presented.

\section{CURRENT STATE OF THE PRACTICE}

The traffic investigation section of the EIS focuses on the determination of anticipated traffic flow characteristics of the proposed project by applying analytical methods that can be grouped under the umbrella of capacity analysis methodologies. In general, the main traffic parameter used in EISs to describe the quality of traffic flow is the Level of Service (LOS). The LOS is a measure used by traffic engineers to describe the effectiveness of elements of transportation infrastructure. The US Department of Transportation (US DOT) defines LOS as " a standard measurement used by transportation officials which reflects the relative ease of traffic flow on a scale of A to $F$, with free-flow being rated LOS A and congested conditions rated as LOS F."

The analytical process to estimate these LOSs involves the utilization of transportation demand models that produce estimates of daily traffic flows for the different alternatives studied. Where available, actual (and recent) traffic counts are used to calibrate the demand models or directly as the basis for the projection of future vehicle flows. In other areas, for example areas in which no existing roads are available, information from similar roads in the general vicinity are used or expert assumptions are made and adopted. For each one of the roadway segments of the different alternatives being studied, those future projected traffic flows are compared to the roadway capacity ${ }^{1}$ of the segments and the determined LOS. Adjustments are made to the ideal lane capacity (usually 2,000 passenger cars per hour for a typical freeway lane) to take into

\footnotetext{
${ }^{1}$ The Highway Capacity Manual defines the capacity of a facility as "the maximum hourly rate at which persons or vehicles reasonably can be expected to traverse a point or a uniform section of a lane or roadway during a given time period under prevailing roadway, traffic, and control conditions."
} 
account the percentage of heavy vehicles in the traffic mix, the design speed, the grade of the segment, the lane width, the presence of center barriers and lateral obstructions, and other factors that affect the maximum traffic flow that the segment can support. The LOS can also be determined for surface streets (i.e., signalized and unsignalized intersections) using methodologies that are different from those applied to freeway segments. All these procedures are presented in the Highway Capacity Manual (HCM2000) [1].

Three different transportation data sources were used for the I-69 SIU 9 traffic analysis [2]. For the regional travel demand, a model maintained by the Memphis Area Metropolitan Planning Commission (MPO) and by TDOT was used. The transportation network for this model included the arterials and the freeways in the region. For the available forecast year (i.e., 2023) the model transportation network included all of the future roadways that are specified in the Memphis Area Long Range Transportation Plan (LRTP), and was augmented to represent the Build Alternative. The software used to model travel demand was the Minicomputer Urban Transportation Planning software (MinUTP), which is a widely accepted highway and transit transportation forecasting software for this type of analysis. The regional model was run for both the Build and No-Build alternatives to forecast traffic flows.

The second source of information was the actual traffic counts provided by the City of Memphis, TDOT, and the Mississippi Department of Transportation (MDOT). This information is, in general, used to calibrate and supplement the travel demand model output. Since there was a discrepancy between the forecast year of the regional model (2023) and the horizon year for the I-69 traffic investigation (2030), a growth factor was used to correct the outputs of the regional travel demand model.

The travel projections provided by the I-69 National Trade Corridor Study was the third data source used in the traffic investigation. The I-69 National Trade Corridor Study Model included new trips that would travel into the region due to the development that is anticipated to be associated with the construction of I-69. These trips were assigned to the roadways within the region by manual assignment.

Although some of this information resides on Geographic Information Systems (GIS) platforms and databases, in general the software that runs the travel forecast models, such as the MinUTP model used in this EIS, requires the inputs to be in a specific format and is not integrated into these GIS platforms. That is, the models and methodologies used to run the traffic investigation are a collection of stand-alone software utilities that require their own inputs, although these inputs are intimately related to spatial information developed under other EIS investigations.

\subsection{PRESSENTATION OF ANALYSIS RESULTS}

Once these models are run and the methodologies described above applied to their results, a large volume of traffic information is generated. In general, in an EIS these results are presented in a tabular fashion, and are reduced just to LOS information, which is not a very meaningful measure for non-transportation experts. Consider, for example, Figure 1 which presents the LOS for segments of I-55 and other major arterials that will become part of the proposed I-69 SIU-9 (a similar table is presented in the EIS for the I-269 facility, with LOS information for both the Build and No-Build conditions). The information presented in the table shown in Figure 1 is very important from the traffic operations point of view; however, it is only meaningful to 
transportation experts who can discern the subtleties that exist between a given LOS and the next level.

TABLE 1-2

PROPOSED I-69 LEVELS OF SERVICE (LOS)

\begin{tabular}{|c|c|c|c|c|c|c|c|c|c|c|}
\hline \multirow{3}{*}{ Location } & \multicolumn{5}{|c|}{ Proposed I-69 } & \multicolumn{5}{|c|}{ No-Build } \\
\hline & \multirow{2}{*}{$\begin{array}{l}2030 \\
\text { ADT }\end{array}$} & \multicolumn{4}{|c|}{$\begin{array}{l}\text { Level of } \\
\text { Service for: }\end{array}$} & \multirow{2}{*}{$\begin{array}{l}2030 \\
\text { ADT }\end{array}$} & \multicolumn{4}{|c|}{$\begin{array}{l}\text { Level of } \\
\text { Service for: }\end{array}$} \\
\hline & & 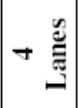 & ○ & 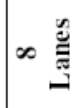 & 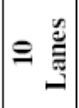 & & 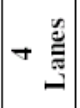 & ○ & 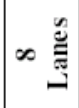 & $\Theta \underset{\tilde{\underbrace{}}}{\stackrel{0}{=}}$ \\
\hline I-55 North of SR 304 & 76,500 & & & $\mathrm{C}$ & & 68,800 & & & $\mathrm{C}$ & \\
\hline $\begin{array}{l}\text { I-55 North of } \\
\text { Nesbit/Pleasant Hill }\end{array}$ & 82,500 & & & $\mathrm{C}$ & & 74,900 & & & $\mathrm{C}$ & \\
\hline $\begin{array}{l}\text { I-55 North of Star } \\
\text { Landing }\end{array}$ & 92,500 & & & D & & 84,900 & & & $\mathrm{D}$ & \\
\hline $\begin{array}{l}\text { I-55 North of Church } \\
\text { Road }\end{array}$ & 100,500 & & & $\mathrm{D}$ & & 92,900 & & & $\mathrm{D}$ & \\
\hline I-55 North of Nail Road & 106,500 & & & $\mathrm{E}$ & & 98,900 & & & $\mathrm{D}$ & \\
\hline I-55 North of SR 302 & 114,200 & & & & $\mathrm{D}$ & 107,200 & & & & $\mathrm{C} / \mathrm{D}$ \\
\hline I-55 North of Stateline & 117,200 & & & $\mathrm{~F}$ & & 110,200 & & & $\mathrm{D} / \mathrm{E}$ & \\
\hline I-55 North of Holmes & 120,200 & & & F & & 113,200 & & & $\mathrm{E}$ & \\
\hline I-55 North of Shelby Dr. & 136,000 & & & $\mathrm{~F}$ & & 129,100 & & & $\mathrm{~F}$ & \\
\hline $\begin{array}{l}\text { I-55 North of Elvis } \\
\text { Presley }\end{array}$ & 144,000 & & & & $\mathrm{E}$ & 137,100 & & & & $\mathrm{D} / \mathrm{E}$ \\
\hline I-240 North of Norris & 124,400 & & & $E$ & & 119,200 & & & $E$ & \\
\hline $\begin{array}{l}\text { I-240 North of S. } \\
\text { Parkway }\end{array}$ & 125,400 & & & $\mathrm{E} / \mathrm{F}$ & & 120,200 & & & E & \\
\hline I-240 North of Union & 89,300 & & & $\mathrm{D}$ & & 84,700 & & & $\mathrm{D}$ & \\
\hline I-240 North of I-40 & 68,900 & & $\mathrm{C}$ & & & 66,500 & & $\mathrm{C}$ & & \\
\hline I-240 North of Jackson & 58,700 & & $\mathrm{C}$ & & & 56,700 & & $\mathrm{~B} / \mathrm{C}$ & & \\
\hline $\begin{array}{l}\text { I-40 North of } \\
\text { Chelsea/Firestone }\end{array}$ & 123,300 & & & D & & 118,500 & & & $\mathrm{D}$ & \\
\hline SR 300 & 50,500 & $\mathrm{D}$ & & & & 48,500 & $\mathrm{C}$ & & & \\
\hline $\begin{array}{l}\text { I-69 West of US } 51 \text { (N } \\
2^{\text {nd }} \text { St.) }\end{array}$ & 45,500 & $\mathrm{D} / \mathrm{C}$ & & & & 43,600 & $\mathrm{~B} / \mathrm{C}$ & & & \\
\hline I-69 North of N. $2^{\text {nd }}$ St. & 49,400 & $\mathrm{D}$ & & & & NA & & & & \\
\hline I-69 North of Watkins & 37,400 & $\mathrm{C}$ & & & & NA & & & & \\
\hline $\begin{array}{l}\text { I-69 North of Cuba- } \\
\text { Woodstock }\end{array}$ & 30,400 & B & & & & NA & & & & \\
\hline I-69 North of SR 385 & 35,900 & $\mathrm{C}$ & & & & NA & & & & \\
\hline
\end{tabular}

Figure 1 Proposed I-69 and No-Build Alternatives - Traffic Analysis Results (LOS) (Source: Interstate 69, SUI \#9 - Final EIS, FHWA-TN-EIS-04-01F, 2006)

Some of the relevant transportation information included in the EIS is presented spatially, but this is restricted to maps showing the trace of the different alternatives, traffic districts, and roadway improvement priority from the LRTP. No results from the traffic investigation are depicted graphically, except for the predicted traffic flows at the freeway interchanges that are part of the project. However, these are not really maps (see Figure 2 for a representation of the predicted traffic flows at the I-69 interchanges in the Memphis city limits) and are another way of organizing the results in a tabular manner.

Regarding heavy trucks (freight), there is some minimal information in the EIS, but it is scattered throughout the report and not specifically presented in a table or graph. Truck volumes 
are very important because they strongly affect traffic conditions (i.e., the level of congestion) and safety.

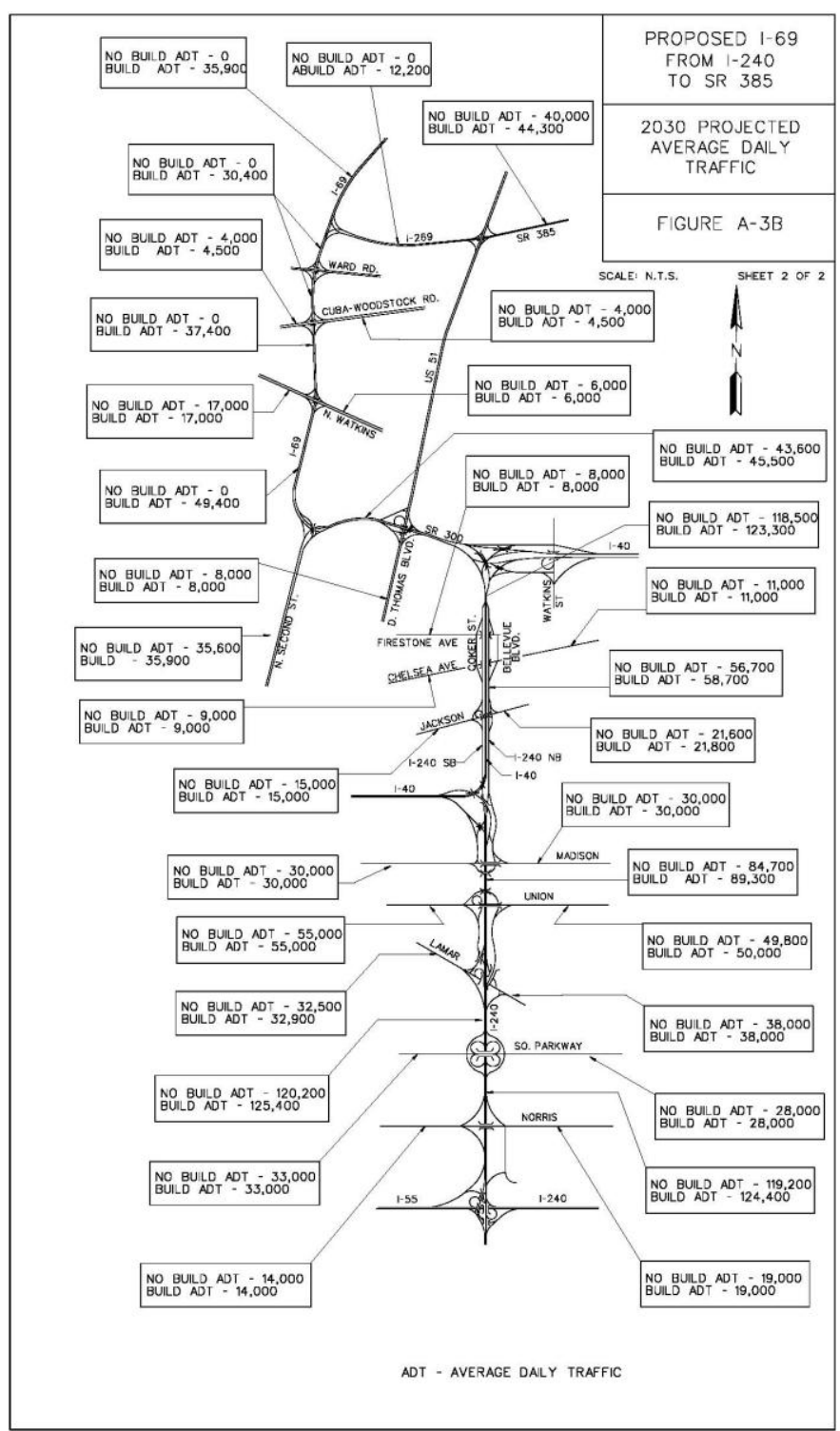

Figure 2 Proposed I-69 - Traffic Analysis Results (Predicted Traffic Volumes at I-69 Interchanges) (Source: Interstate 69, SUI \#9 - Final EIS, FHWA-TN-EIS-04-01F, 2006)

\subsection{RESULT PRESENTATION SHORTCOMINGS}

Traffic information is spatial in nature. A traveler choosing a route from home to work considers all the alternative routes between these two points and does not make decisions based on a segment of roadway at a time. In consequence, representation of traffic information that is not spatially depicted, as in the EIS case, is much more difficult to comprehend.

Traffic investigation results associated with the different alternatives being studied, as well as their impacts on travelers and on the regional commerce are difficult to appreciate when 
presented in tabular form. Also, results and information presented in this format does not lend itself to further analysis. Consider Figure 1 again. It is easy to understand that a segment of freeway operating under LOS D is worse (more congested) than one under LOS C, but how more congested? Also, because the information is not presented spatially it is difficult to grasp the impact (in terms of congestion and expected delays) that the Proposed and No-Build Alternatives would have for a traveler who, for example, commutes to work in downtown Memphis from South Memphis.

Spatial information technologies, on the other hand, offer a clear benefit in bridging the gap of analysis and depiction of results. When comparing the tabular matrix of future conditions (Figure 1) to spatial depictions of the same information (see Figure 3 and Figure 4) it can be seen that the system is predicted to worsen in specific areas due to the proposed project. The SouthMemphis to downtown commuter discussed above is expected to travel through longer stretches of freeways under LOS F (failure = stop and go freeway traffic) in the Proposed Alternative than in the No-Build option. Furthermore, the use of technologies such as Geodetic Portable Document File (GeoPDF) would facilitate these comparisons even more by allowing the overlayof the two maps shown in Figure 3 and Figure 4, and turning one layer off to quickly identify the differences between the two alternatives.

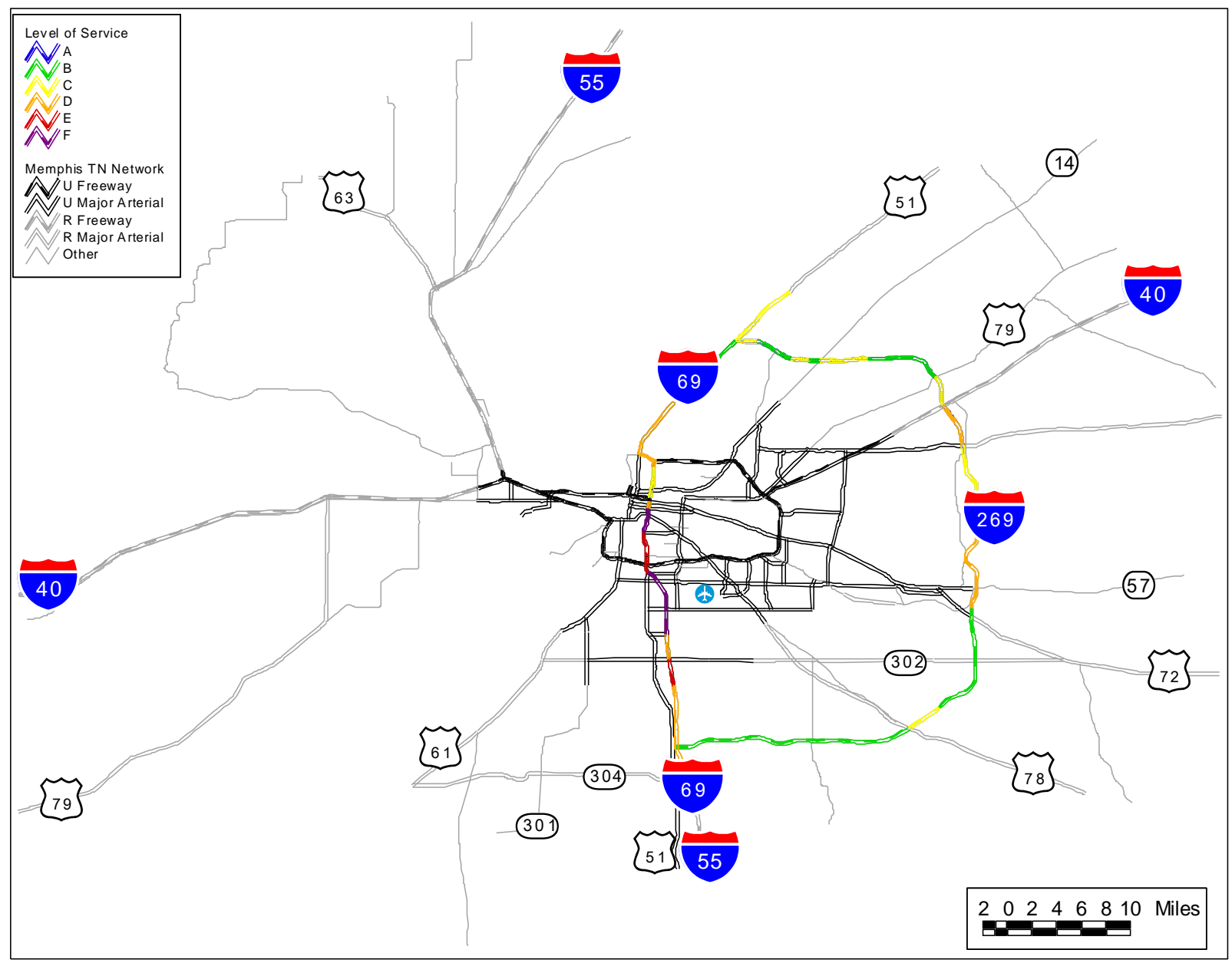

Figure 3 Proposed I-69 and I-269 - LOS 


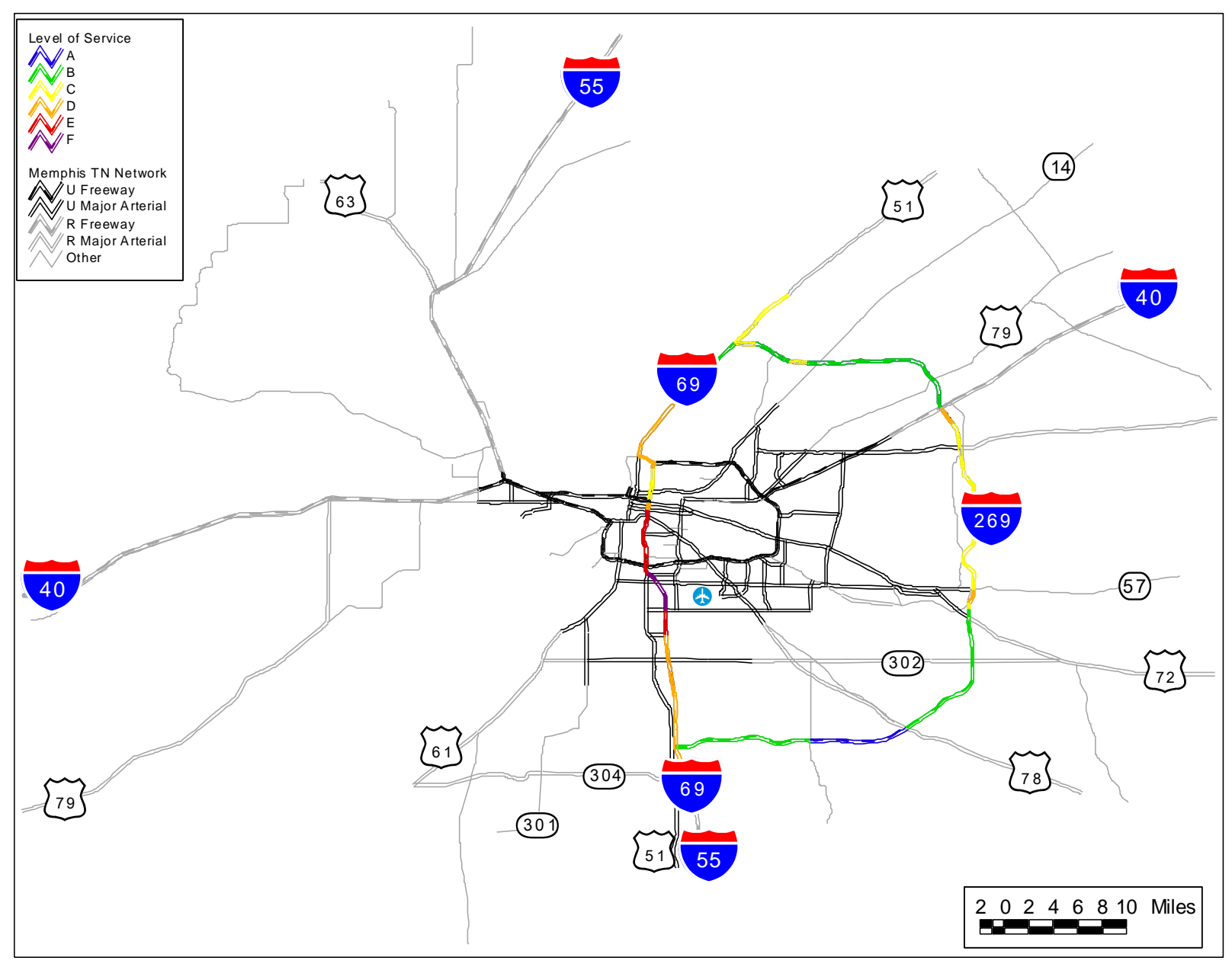

Figure 4 No-Build Alternative I-69 and I-269 - LOS

As discussed previously, only in few instances is the transportation information in the EIS shown in a graphical form. Specifically, regarding the results of the traffic investigation only, predicted traffic flows at freeway interchanges along the proposed project are arranged and shown in a spatial-tabular format (see Figure 2 for an example). Although this is an improvement with respect to presenting results in tables, it still requires carefully reading of the information presented, and it is difficult to see the "entire picture" in terms of how the traffic flows are distributed in the region.

Compare the information shown in Figure 2 with that of Figure 5. Both figures show information related to traffic flows for the forecast year; the former total volumes and the latter truck volumes. The information presented in Figure 5 is easier to understand than that of Figure 2 , and some conclusions can be derived by simply glancing at the map. For example, it is clear that the east-west bound I-40 will carry larger truck volumes than the north-south bound I-55 (these heavy truck volumes will certainly change when considering the proposed I-69 in its totality as discussed in Section 3.2.2). Notice that even though I-55 is predicted to carry lighter heavy vehicle flows than I-40 for the No-Build Alternative, there is significant truck volume on segments south the airport (i.e., south of SR 175, E. Shelby Dr.). Although these heavy truck volumes are considered in the calculation of the LOS (i.e., Figure 4 shows these segments 
operating under LOS D or E) and therefore in the expected congestion levels that will be experienced in this area, the presence of a large percentage of heavy vehicle in the traffic mix increases the chance and severity of crashes. In other words, the LOS alone does not provide all the data that is needed to make informed decisions.

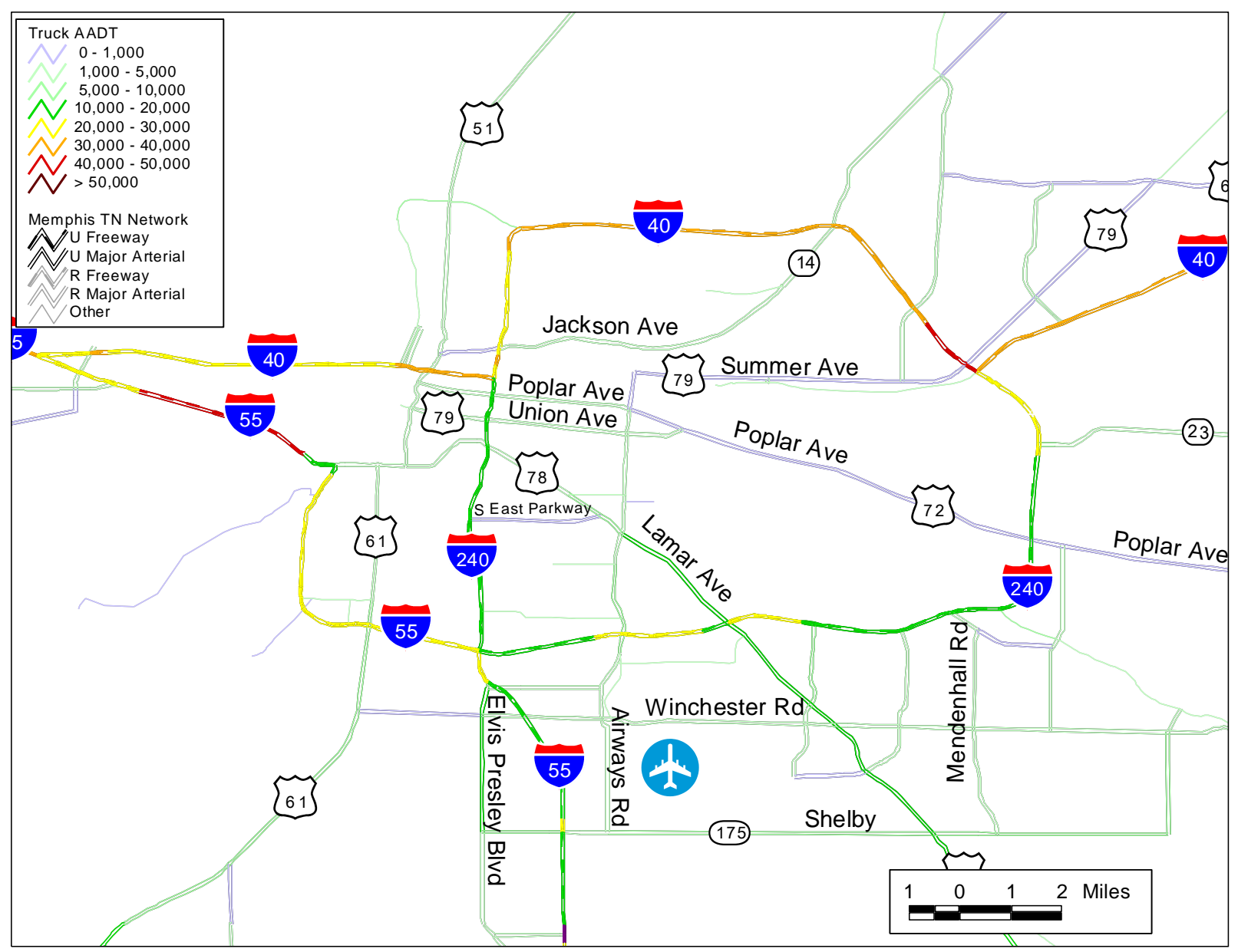

Figure 5 No-Build Alternative - Truck Annual Average Daily Traffic (AADT Forecast Year)

\section{PROPOSED APPROACH}

The current state of the practice in terms of the traffic investigations for EIS has two main shortcomings. The first one is related to the information that is necessary to conduct the traffic analysis, specifically with the lack of integration among the different models and the sources of information that, in general, reside in GIS databases. The second shortcoming is in the presentation of the results, both in terms of the appearance and formatting as well as content. Spatial information technologies can decrease the negative effects of, and even eliminate, these shortcomings by making the relevant information that is input to the models more complete and readily available, and by providing the means to communicate the results in a more clear and efficient manner. The application and use of CRS\&SI technologies will therefore improve and expedite the traffic investigation part of the EIS process. 


\subsection{INTEGRATION OF TRAVEL DEMAND MODELS AND CRS\&SI TECHNOLOGIES}

Travel demand forecasting models are used to predict changes in travel patterns as well as the utilization of the transportation system resulting from changes in demographics, regional development, and transportation supply. In order to conduct the analysis, the region is first divided into zones that have some common socioeconomic characteristics and land use. The transportation network that connects these zones is used as the basic network for the analysis. Traditionally, a four step process consisting of a trip generation model, a trip distribution model, a modal split model, and a traffic assignment model, is then used for travel demand forecasting.

The trip generation component estimates the number of trips that originate in each zone of the study area. Those trips, which are further classified by purpose (e.g., work-end trips, homeend trips, shop-end trips, etc.), are generated by relating the frequency of trips to the characteristics of the individuals, of the zone, and of the transportation network. The trip generation model is further subdivided into trip production and attraction sub-models, which in turn use different methodologies, which depend on the data availability, to estimate the number of trips that each zone attracts and produces.

Trip distribution models are used to predict the spatial pattern of trips (or other flows such as, for example, commodity flows) between origins and destinations. The trip distribution models range from the standard gravity model (in which the interaction between two zones declines with increasing distance, time, and cost between them, and increases with the amount of activity at each zone) to sophisticated models such as doubly-constrained trip distribution models and triproportional models. The output of the trip distribution model is the O-D (origin-destination) matrix for the area under study which specifies the number of trips from zone $i$ to zone $j$, where $i$ and $j$ vary from 1 to $n$ (the maximum number of zones).

The modal split models then take that O-D matrix and assign trips to different transportation modes according to mode availability (e.g., transit, car, carpool, walk, bike, etc.), trip distance, and socioeconomic characteristics of the travelers. Finally, a traffic assignment model is used to determine the routes that will be followed from a give origin $i$ to destination $j$. Traffic assignment models vary from simplistic all-or-nothing models (assignments using the paths with the shortest distance between $i$ and $j$, disregarding travel time) to sophisticate models such as user equilibrium traffic assignments (considers travel time between origin and destination), dynamic traffic assignments (considers variations in travel time between origin and destination), and multi-modal/multi class traffic assignments (considers value of time and network use restrictions). The results of the traffic assignment model are the forecasted traffic volumes on each roadway segment of the network. Those, together with the geometric characteristics of the segment and other transportation parameters, are used to estimate, among other measures, the LOSs for those roadway segments.

The application of these different models makes travel demand forecast a complex and challenging task. The integration of travel demand forecasting and CRS\&SI technologies provides many advantages and can help reduce and/or eliminate most of these challenges. Firstly, the CRS\&SI technologies increase the accuracy of the planning models (e.g., distances are based on the actual geometry of the roadways and a correct representation of freeway interchanges). Secondly, the entire modeling process becomes more efficient since the data preparation is significantly facilitated and potential errors that could cause modeling problems are identified earlier through the database and visualization capabilities provided by the CRS\&SI 
technologies. In other words, the travel demand model is easier to implement and maintain. Thirdly, the model can take advantage of CRS\&SI-derived measurements and incorporate those directly in the modeling process. For example, it is possible to make different modeling assumptions for each zone and also, different modeling equations can be derived and applied for different geographic areas. Fourthly, CRS\&SI technologies provide unmatched visualization capabilities that enable the production of high quality maps. This, in turn, facilitates and enhances the presentation of large amounts of data, which is a need in the case of the EIS traffic investigation. Furthermore, the use of technologies such as GeoPDF would make comparisons of result very easy to make. Finally, the integration of travel demand models and CRS\&SI technologies facilitates analyses that are not possible otherwise. For example, it is possible to calculate indicators related to land use information and socioeconomic characteristics (number of vehicles/urban area square foot, classification of roads by degree of saturation flow, and others) which additional information for each alternative considered thus improving the decision making process. It is also easier to use other models, such as for example noise and pollution models, since it is possible to correlate forecasted traffic volumes for a given segment of roadway with population within a certain buffer zone around that segment of freeway.

Over the years there have been many attempts to integrate existing and stand-alone travel demand models with CRS\&SI technologies. The travel demand model used in the EIS focus of this study (i.e., MinUTP) is one of the most widespread models for this type of analysis and has been integrated with GIS platforms such as the Environmental Systems Research Institute, Inc. (ESRI) ArcInfo. For example, Thomas and Hoffman [3] describe an application composed of two modules. The first one is a shapefile translation utility specifically developed for MinUTP networks, and the second is a set of tools that facilitate editing of the converted networks in ArcView. The latter closely mimic the editing capabilities used by MinUTP's network editor, thus helping the analyst that is not familiar with ArcView software's editing procedures. This eliminates one of the important barriers that impede the integration of travel demand models with CRS\&SI technologies. Similar utilities aimed at merging MinUTP and GIS technology were developed and described by Nguyen-Luong [4] and by Matzzie and Rogers [5].

Although not used in the EIS that is the subject of this project, the EMME (Equilibre Multimodal/Multimodal Equilibrium) is another widely utilized travel demand model. Similarly to the MinUTP case, there have been efforts to integrate the EMME model with GIS technology. Li et al. [6] describe an application developed in MatLab that permits the interchange of information between EMME/2 and ArcInfo. As an example of the integration between Arc/Info and EMME/2, the authors apply the tool developed to the road network of Lyon County, Minnesota.

Parallel to these efforts, modelers have developed software that integrates GIS capabilities and travel demand modeling, as well as other traffic and transportation models, in one single package. For example, version 3 of the EMME model (EMME/3) provides an ArcInfo plug-in that permits access to geo-referenced maps and GIS data directly [7]. The native EMME and ArcGIS map layers appear beside one another providing visualization, network editing, analysis, and report generation capabilities. The software permits re-using existing enterprise GIS assets and also provides shapefile exporting capabilities.

Another powerful transportation modeling platform is TransCAD [8]. The software provides modules for travel demand forecasting, routing, public transit, logistics, site location, and territory management. It has its own GIS engine, with special extensions for transportation, offering mapping, visualization, and analysis tools designed for transportation applications. 
TransCAD supports over 50 file types and more than 100 GIS and CAD formats both for import and export of data, thus permitting an easy integration with CRS\&SI technologies.

\subsection{PRESENTATION OF RESULTS}

As discussed previously, one of the most important shortcomings of the current state of the practice of the traffic investigation included in EISs is the presentation of the results. In this regard, there are two major drawbacks. The first one is related to the depiction of results, which are currently presented in a tabular or descriptive text manner. In this case, there is a clear advantage in using CRS\&SI technologies, which provide powerful tools to present traffic-related parameters, both spatially and temporarily. By concisely presenting large amounts of traffic related information that is easy to understand, CRS\&SI technologies can aid the decision-making processes regarding policy decisions and also help the population in the affected area to better understand the effects of the different alternatives under consideration (including the do-nothing alternative). For example, the use of technologies such as GeoPDF greatly facilitate the comparisons of the outcomes of the different alternatives by allowing the overlaying of maps showing the results of the scenarios considered and permitting layers to be turned off and on to quickly identify the differences among these scenarios. This type of technology, therefore, plays a key role in presenting the results to policy makers and the public.

The second drawback deals with the content of the information presented. The information derived from the travel demand models can be used to generate traffic parameters that are more meaningful to non-transportation experts than LOSs. The integration of travel demand models currently being used by the agencies in charge of generating this information with CRS\&SI technologies as described above, or the adoption by these agencies of software that already combine both technologies, can provide the means to calculate and display these other traffic parameters. For example, volume to capacity ratios and delays are measures that convey similar information as LOSs, but that resonate better with audiences not trained in the transportation/traffic operation field. Another important parameter that needs to be explicitly added to the information presented is freight. While truck volumes play a central role in the computation of LOS and other traffic parameters, the information is also very important to gauge safety and security. Higher percentages of trucks in the traffic mix can increase the severity of crashes, if not their frequency. Also, in the case of security events that require closing segments of freeways and re-routing traffic to surface streets, special considerations need to be taken into account for heavy vehicles since they have special requirements in terms of turning radius and height clearances ${ }^{2}$. Unless freight volumes are explicitly presented as part of the traffic investigation, it is not possible to include these considerations into the decision making process. A discussion related to these additional traffic parameters, which are divided into roadway utilization parameters and freight information, is presented below.

\subsubsection{Roadway Utilization}

This section describes several traffic parameters that can help to better understand the expected traffic conditions in the study area for the No-Build, Proposed, and even do-nothing

\footnotetext{
${ }^{2}$ Another advantage of having the traffic information in spatial databases and accessible through CRS\&SI technologies is that the re-routing of heavy vehicles can be done efficiently by using the tools provided by these technologies to find surface street diversion routes that can accommodate these requirements.
} 
alternatives. Those parameters include LOS (since this is traditionally the measure used in EISs' traffic investigations to describe traffic conditions), volume-to-capacity ratios, and delays. In particular, the latter is a parameter that is much easier to understand than LOS since everyone has experienced delays at one time or another or even daily as may be the case in large urban areas such as Memphis, Tennessee.

The decision of whether to build or not a new transportation facility, or to improve existing facilities affects not only the traffic on those roads, but also across the region. Usually, the EIS only presents the results of the traffic investigation that correspond exclusively to the facilities under consideration, although the travel demand and other transportation models used in the analysis produce results for the entire network. The problem is that it would take a considerable amount of space in the report to add this information in the traditional tabular format. This, however, is not a constraint when using CRS\&SI technologies. Moreover, the use of technologies such as GeoPDF can reduce the report space requirements even further.

\subsubsection{Levels of Service}

As discussed previously, the LOS is the traditional traffic parameter used in EISs to convey the results of the traffic investigation. It ranges from LOS A (the least congested conditions, with free-flow speeds) to LOS F (system failure). The latter implies very congested conditions; however, not all LOS F are the same. For example, on two similar segments of freeway (i.e., same geometry, grade, lateral obstructions, heavy vehicle percentage, etc.) operating under LOS $\mathrm{F}$, the one with the higher traffic volumes would experience congested conditions for a longer period of time. This is why other parameters such as volume-to-capacity ratios and delays are better at portraying traffic conditions, especially under congested conditions.

Because the present study did not have access to the travel demand model used in the EIS traffic investigation (nor to its results for the entire area), the FHWA Freight Analysis Framework Database (see section 3.2.2.1) was used to complement the information presented in the EIS report. This database has not only freight information, but also general traffic information, roadway capacity information, and other relevant parameters for the entire nation. Regarding temporal data, the database contains information for 2002 and for 2035. Those base and forecast years are different from those considered in the EIS (i.e., 2030 for the forecast year). Therefore, the information presented below, although close to what the travel demand model would predict, is only for depiction purposes and to show how CRS\&SI technologies can convey traffic parameters in an easier to understand manner.

Figure 6 and Figure 7 show the LOS for the entire freeway system in the area for the proposed and No-Build Alternatives. Compare, for example Figure 6 with Figure 3 (which just shows information provided in the EIS traffic investigation). It is possible to see that I-40 and I240 in Memphis will operate under heavy congested conditions as indicated by the LOS shown in the maps for these facilities. In particular, the south Memphis area freeway system (which provides access to the Memphis Airport) would operate under very congested conditions. This conclusion is easily made just by looking at the map presented in Figure 6. On the other hand, by reading the results of the traffic investigation presented in the EIS it is possible to conclude that I-55/I-69 will be affected, but not that the entire freeway system in south Memphis will be congested since this information, due to space constraints, is not included in the report. 


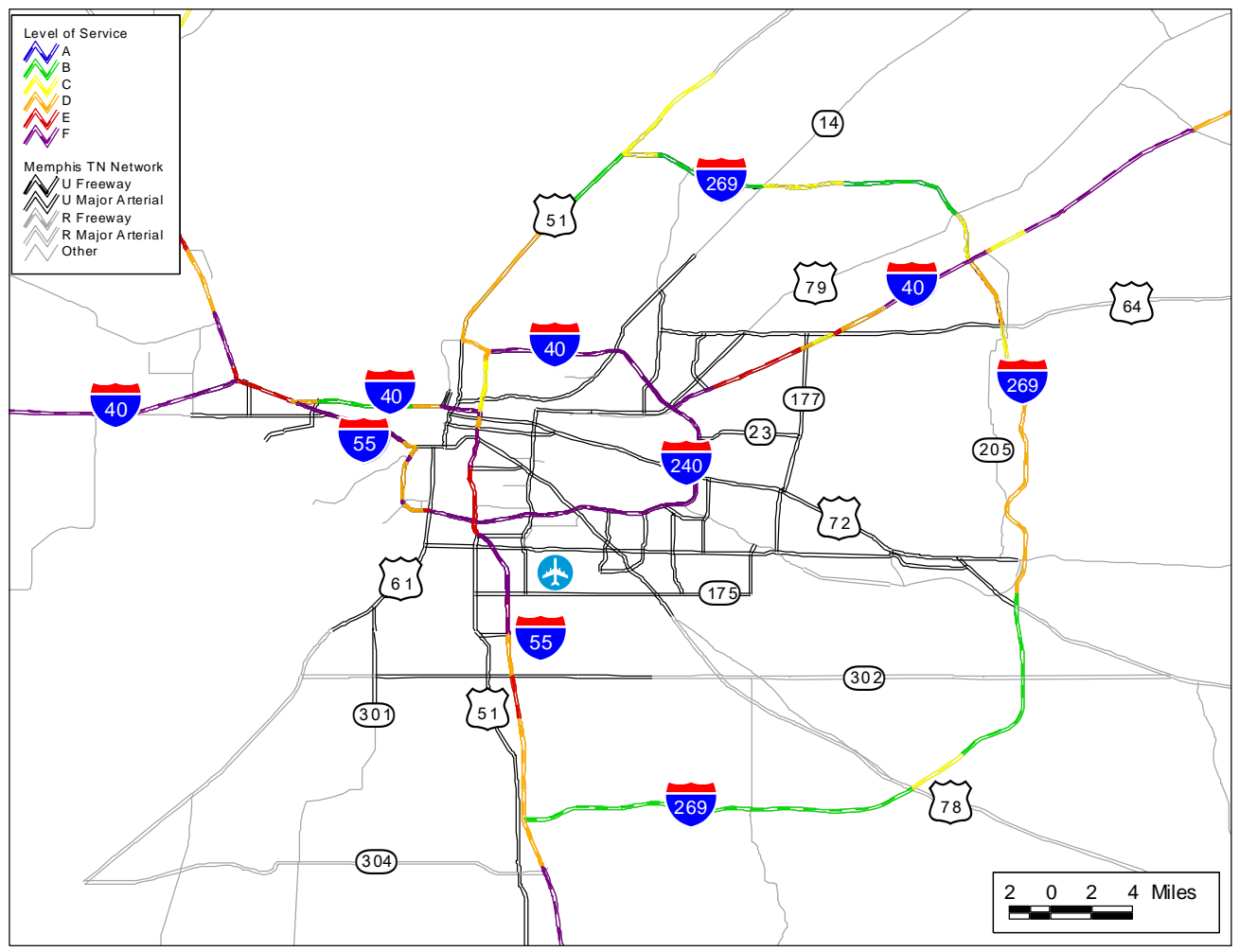

Figure 6 Proposed I-69 and I-269 -LOS for the Entire Highway System (Forecast Year)

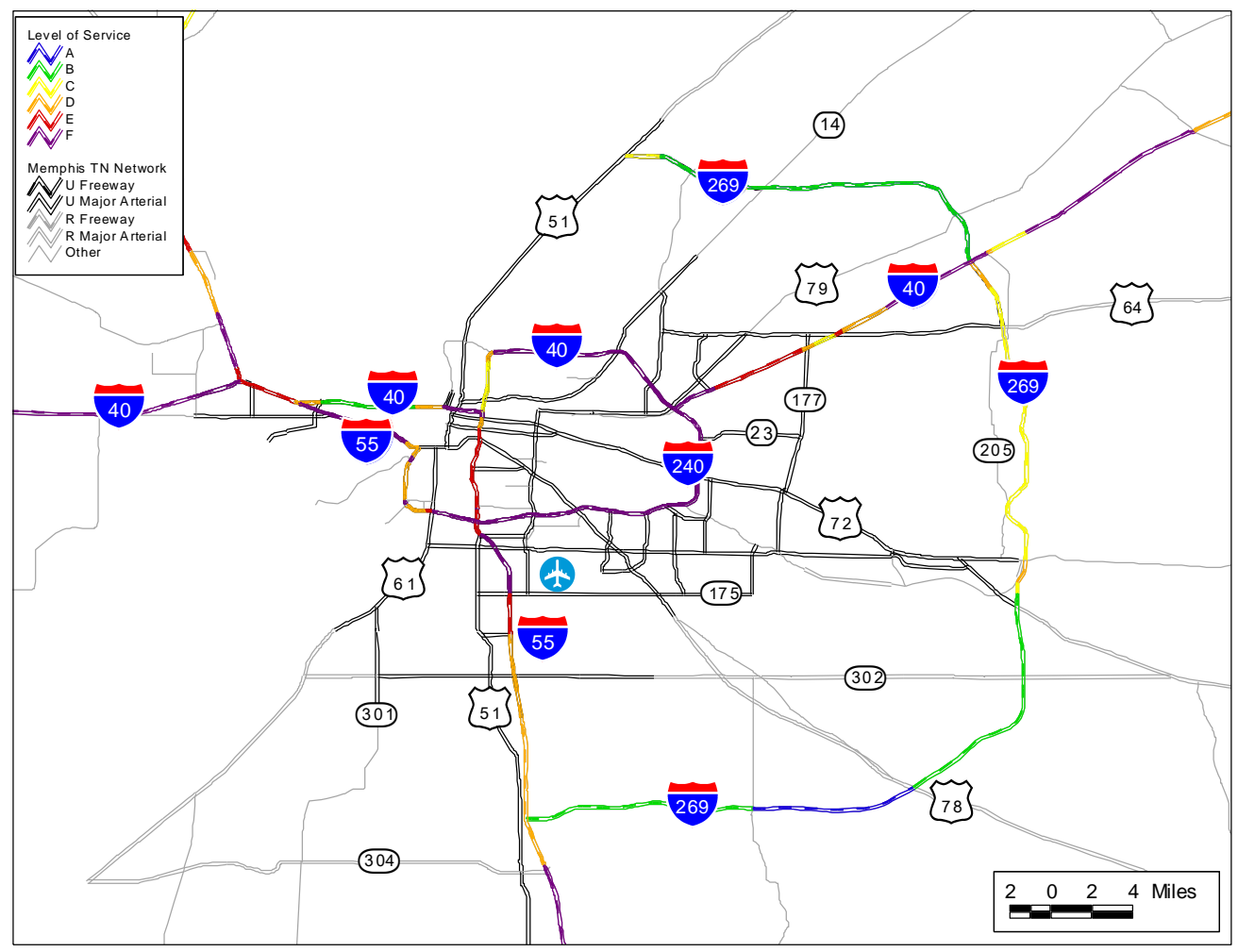

Figure 7 No-Build Alternative - LOS for the Entire Highway System (Forecast Year) 


\subsubsection{Volume-to-Capacity Ratio}

The volume-to-capacity (v/c) ratio is a key factor in the computation of LOS, but it does not reflect the rather subjective nature of the latter, which assumes that perceptions of congestion are consistent across the nation. The v/c ratio compares roadway demand (traffic volume) with roadway supply (carrying capacity).

Figure 8 and Figure 9 show the v/c ratios for the entire area (including freeways and arterials) for the No-Build Alternative for the base and forecast years. The figures show the segment of roadways that are operating at below capacity (uncongested traffic conditions), at capacity, and above capacity (congested traffic conditions). By comparing the two figures, it is easy to see how traffic conditions will deteriorate in the region if no improvements/expansions of the transportation network are accomplished.

Notice that the segments that are operating above capacity (v/c >1) correspond to LOS F or heavy congested conditions; however, the v/c ratios permit further classification of these conditions as shown in the figures. This classification provides an indication of the duration of the congested period for the different segments of roadways operating above capacity.

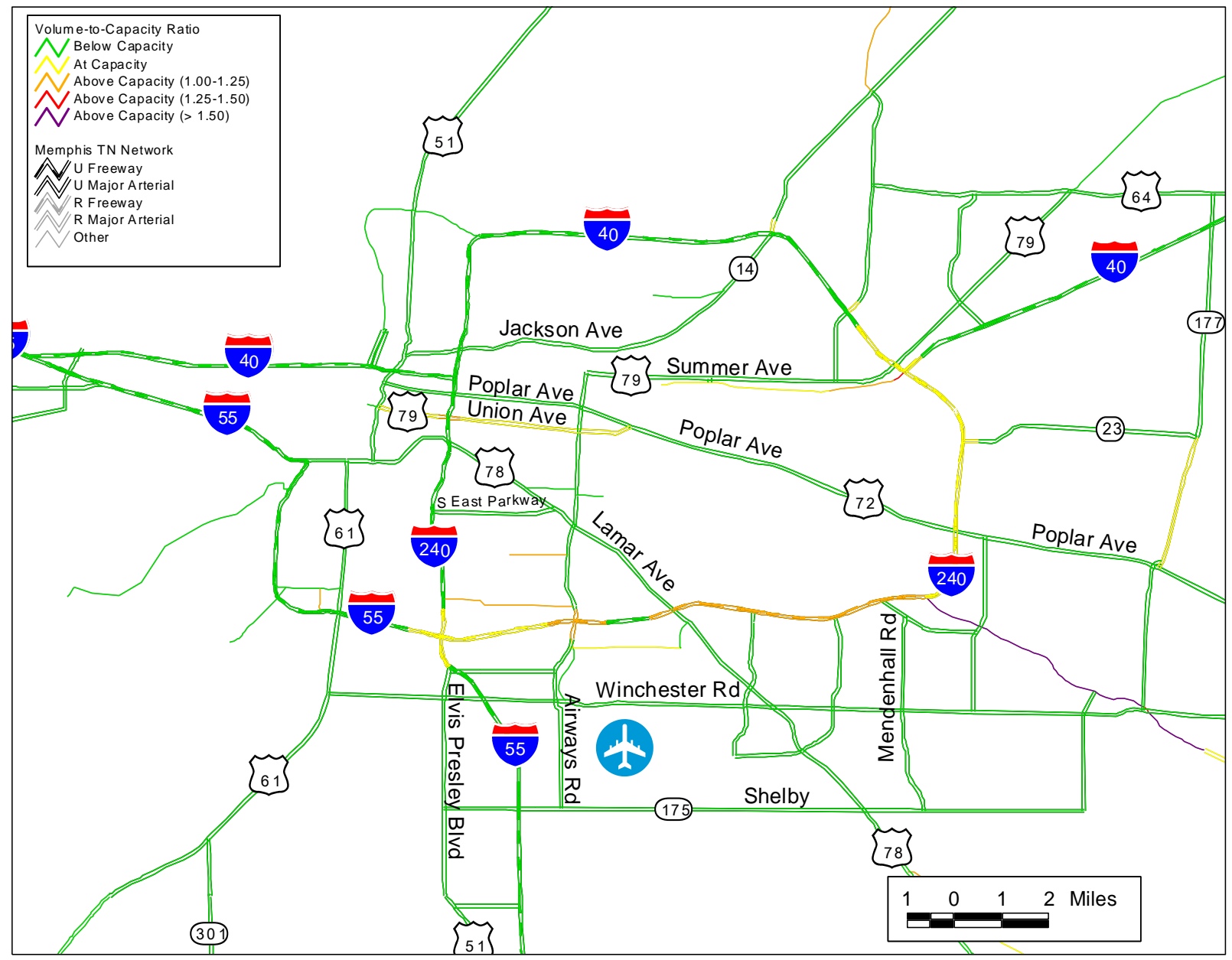

Figure 8 No-Build Alternative - Volume-to-Capacity Ratio (Base Year) 


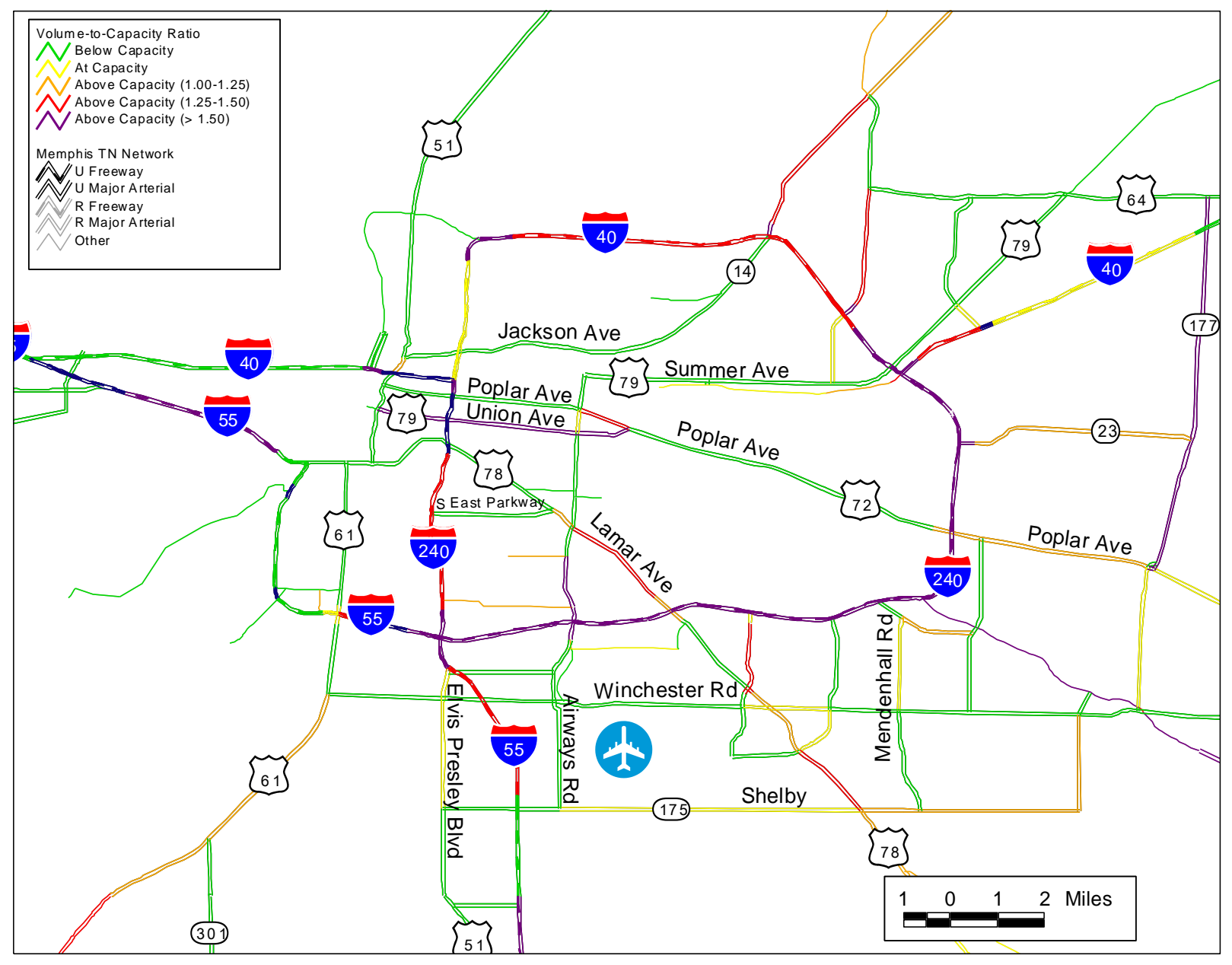

Figure 9 No-Build Alternative - Volume-to-Capacity Ratio (Forecast Year)

\subsubsection{Delays}

Delay is perhaps the easiest traffic parameter to understand by the public and decision makers, since everyone at one point or another has experienced it. In Figure 10 to Figure 13 the delay is presented as seconds per mile traveled, and it was computed by calculating for a given segment of roadway, the difference in travel time for projected traffic conditions and the freeflow travel time. Notice that for the forecast year, almost the entire I-240/I-40 loop experiences delays that are larger than 2 minutes per mile (see Figure 13). 


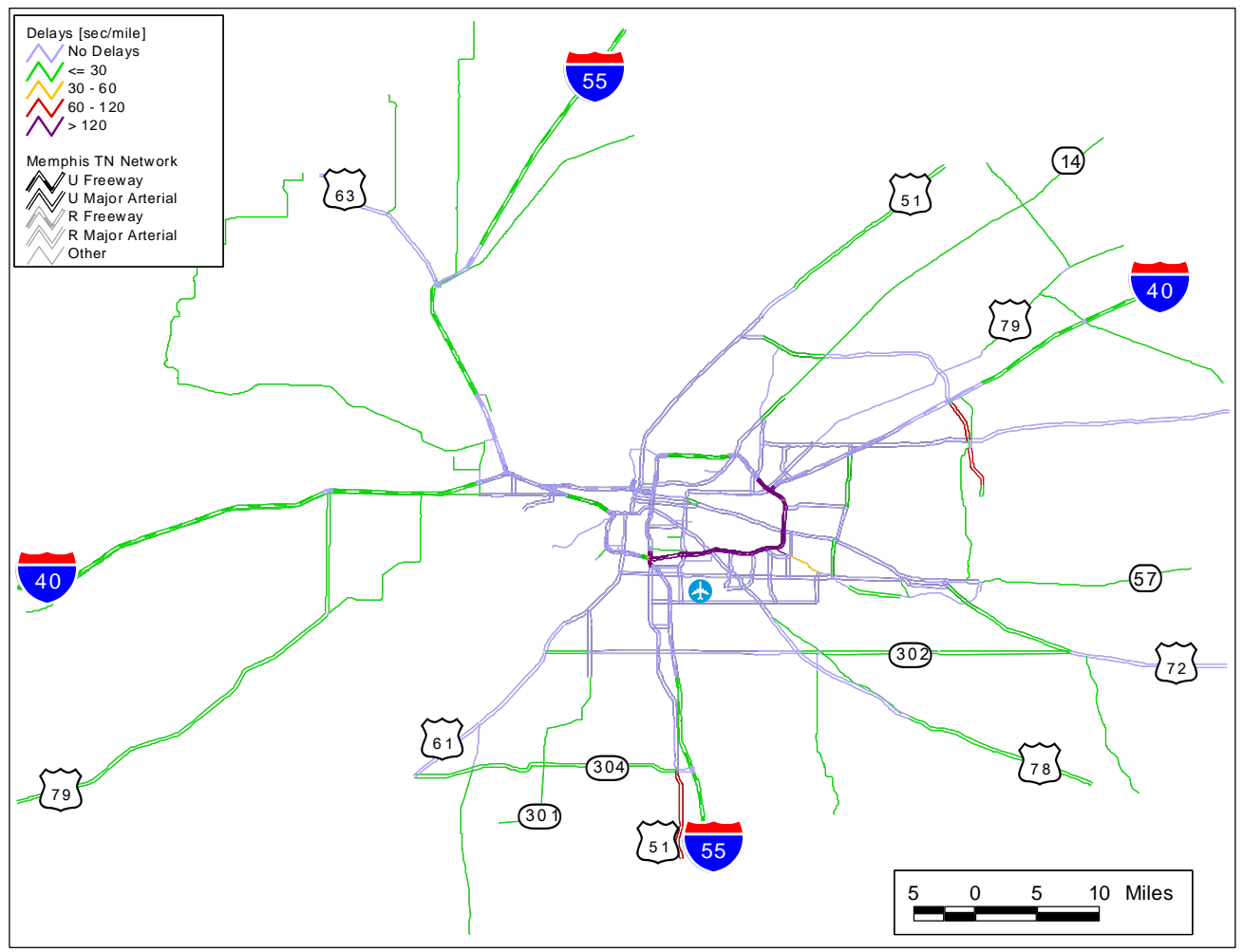

Figure 10 Existing System - Delays (Base Year)

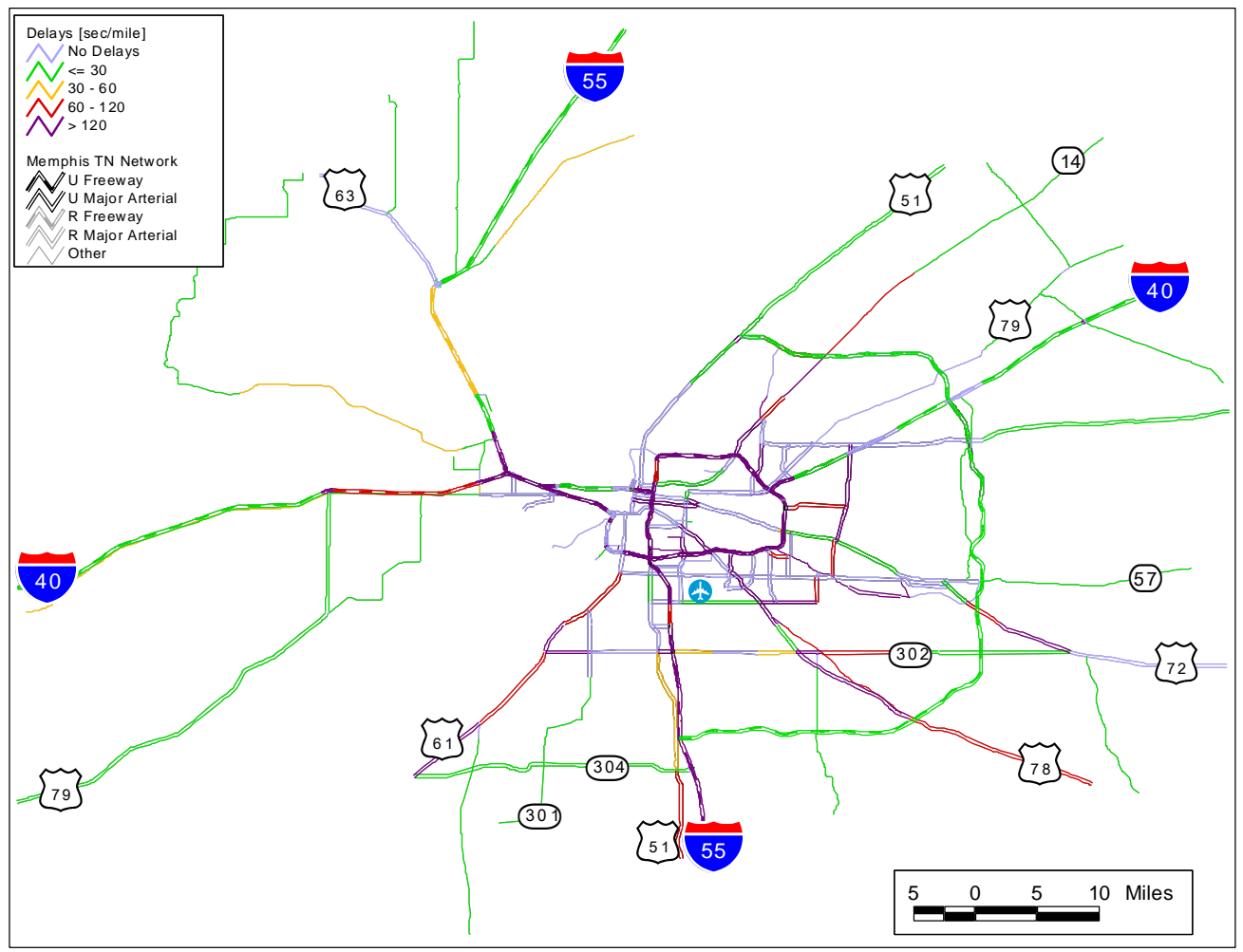

Figure 11 No-Build Alternative - Delays (Forecast Year) 


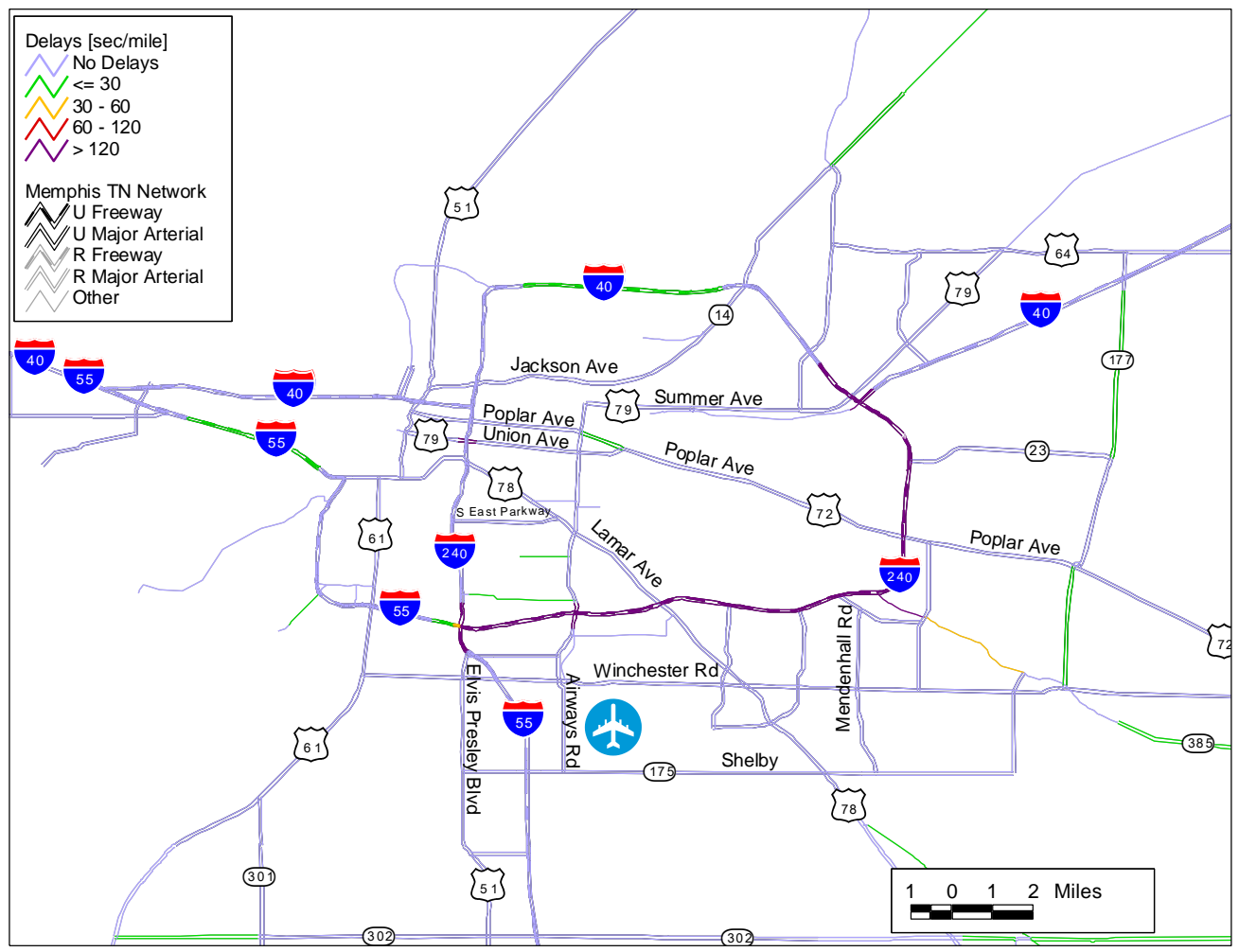

Figure 12 Existing System - Downtown and Airport Area Delays (Base Year)

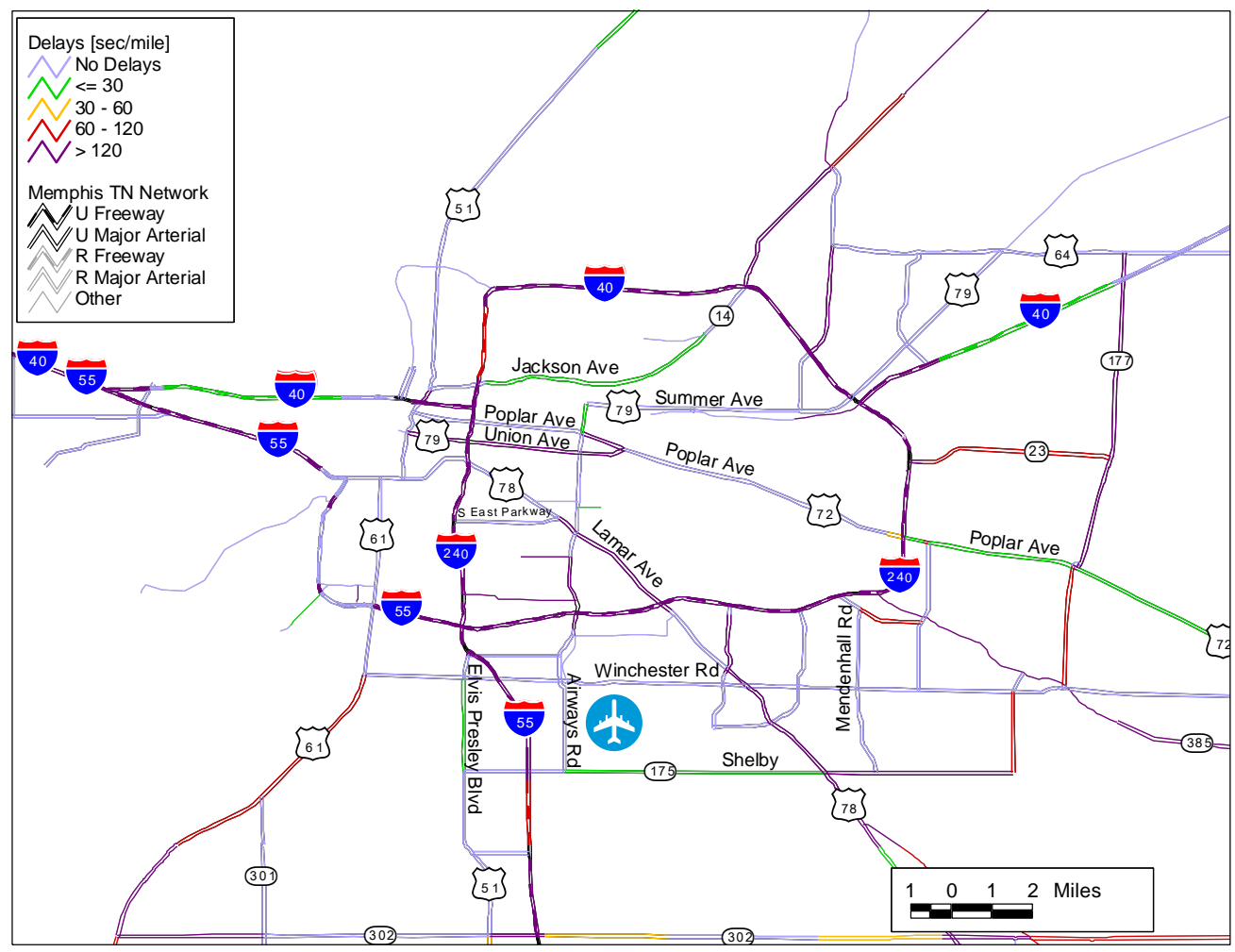

Figure 13 No-Build Alternative - Downtown and Airport Area Delays (Forecast Year) 


\subsubsection{Traffic and Freight Flows}

Traffic flow determination for passenger cars, transit, and local and through freight, is one of the main tasks of the EIS. While forecasts of the flows for the first three types of modes are determined using data and travel demand models that belong to agencies in the region of the study, increases in national level freight flows that could affect that region are not easy to obtain. And even if they are determined (e.g., the EIS subject of the present study indicates that freight flows were obtained from the I-69 National Trade Corridor Study), in general, those freight flows are not discussed in the EISs with the level of detail that is needed.

Truck volumes are very important because they strongly affect traffic conditions (i.e., the larger the proportion of trucks, the higher the level of congestion) and safety (i.e., crashes involving trucks are more severe than those with only passenger cars). Heavy vehicle flows also have an effect on security as discussed previously. To assist with the determination of freight volumes, there is source of information that is publicly available: the FHWA Freight Analysis Framework (FAF). Using the information provided in the geo-referenced FAF database, this subsection discusses the representation of freight flow information.

\subsubsection{Freight Analysis Framework}

The Freight Analysis Framework (FAF) was developed by the FHWA to understand and forecasted commodity movements in the U.S. [8]. FAF includes estimates of commodity flows among states, sub-state regions, and major international gateways, as well as the freight transportation activity (i.e., freight volumes by mode) that those commodity flows generate. The framework also forecasts future flows among regions and assigns these flows to the corresponding modal networks. The system includes an origin-destination database of commodity flows among regions, as well as a network database in which flows are converted to truck payloads and related to specific routes. That is, flows are estimated at the county-to-county level by mode and commodity and assigned to highway, railroad, waterway, and air networks. The modes of transportation include trucks (both private and for-hire trucks), rail (common carrier or private railroad), water (shallow draft, deep draft and Great Lakes shipments), air (includes truck-air), truck-rail intermodal, and pipeline. Version 2.2 of the freight framework (i.e., the current version) excludes all foreign-to-foreign shipments via the United States.

The FHWA Freight Management Operations website [8] includes geographical files for the FAF2 Commodity Origin Destination Data, both in ESRI and TransCAD format. Those files are designed to facilitate the utilization of the FAF2 commodity origin destination data and are publicly available. A summary of the information contained in the associated database file is shown in Table 1. 
Table 1 - Variables Contained in the FAF Database File (FAFDATA.DBF)

\begin{tabular}{|l|l|}
\hline Field & Field Description \\
\hline ID & Unique identification number \\
\hline VERSION & Used for maintaining consistency across data files containing alternate releases of the FAF. \\
\hline AADT02 & HPMS annual average daily traffic for year 2002 \\
\hline AADTT02 & Year 2002 truck volume based on HPMS average truck percentage \\
\hline FAF02 & FAF 2.2 truck flow based on freight demand model and FAF 2.2 O-D database \\
\hline NONFAF02 & Local truck traffic that is not part of FAF 2.2 flow \\
\hline AADT35 & Annual average HPMS daily traffic. Estimated using the HPMS traffic growth factor \\
\hline AADTT35 & Year 2035 truck volume based on HPMS average truck percentage and traffic growth \\
\hline FAF35 & FAF 2.2 truck flow based on freight demand model and FAF 2.2 O-D database \\
\hline NONFAF35 & Local truck traffic that is not part of FAF 2.2 flow \\
\hline CAP02 & Estimated capacity using HCM 2000 methodology \\
\hline SF02 & Service flow volume/hour \\
\hline VCR02 & 2002 volume to capacity ratio \\
\hline SPEED02 & 2002 congested speed miles/hour \\
\hline DELAY02 & 2002 link delays in hour \\
\hline CAP35 & Estimated capacity using HCM 2000 methodology \\
\hline SF35 & Service flow volume/hour \\
\hline VCR35 & 2035 volume to capacity ratio \\
\hline SPEED35 & 2035 congested speed miles/hour \\
\hline DELAY35 & 2035 link delays in hour \\
\hline
\end{tabular}

Source: FHWA Freight Management Operations Website

\subsection{Freight Information}

Using the national FAF database, from which the Memphis region was extracted, Figure 14 presents information on expected increases in freight volumes between the base and the forecast year. Notice, for example, that the area around the Memphis Airport is expected to experience large $(>100 \%)$ increases in freight volume, on both the surrounding arterials and freeway segments. This information does not include the increases in freight that the I-69 corridor, once fully completed, will bring to the area. The consequences of these truck volumes increases are greater degradation of the traffic-flow quality (e.g., on a level terrain freeway a heavy truck is equivalent to approximately 2 passenger cars) and safety (crashes involving heavy vehicles are more severe than those involving only passenger vehicles) conditions. 


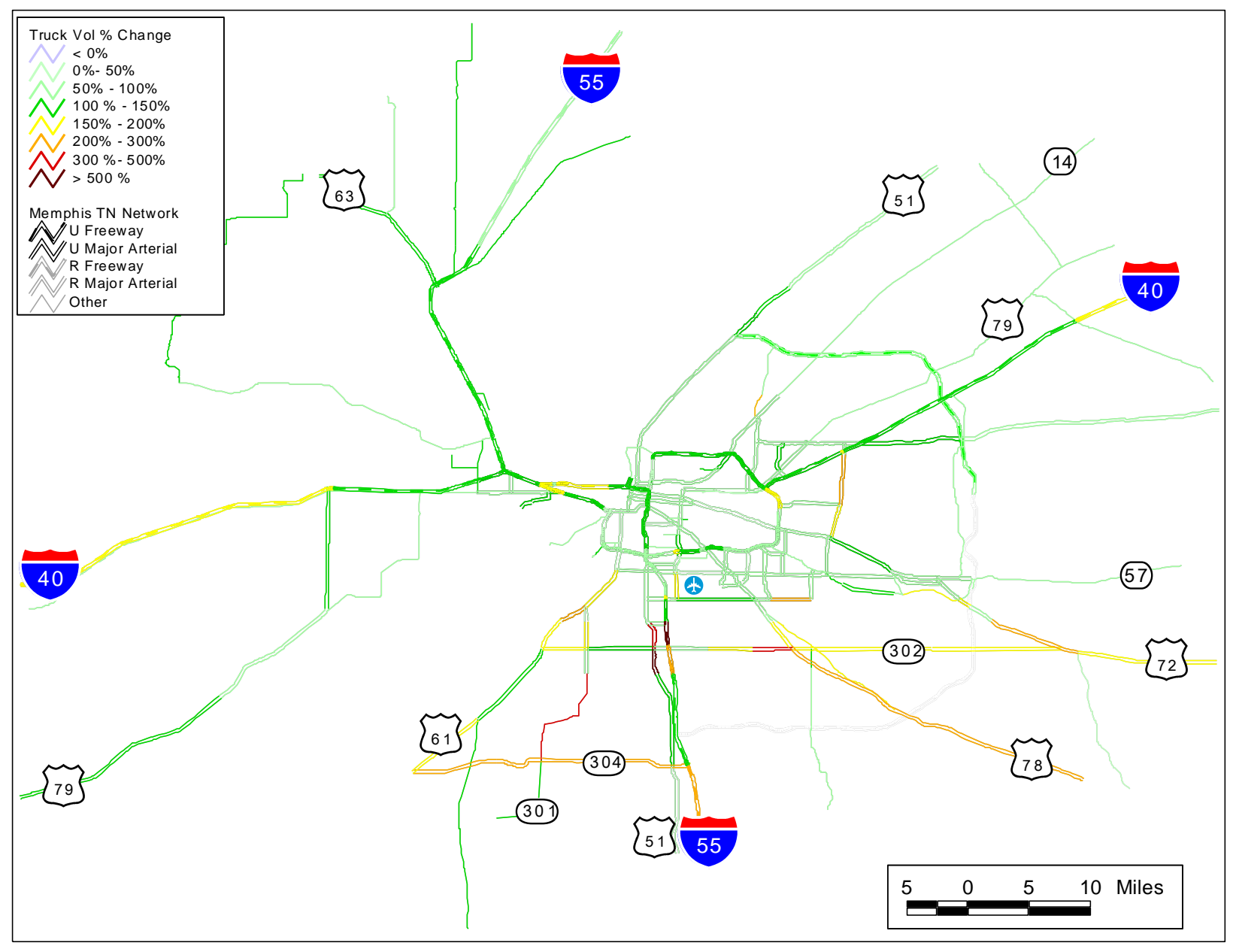

Figure 14 No-Build Alternative - Freight Volume Change (Base to Forecast Year)

Although changes in truck volumes from the base to the forecast year can provide inferences about traffic conditions, a more accurate measure to evaluate the impact of freight is to consider the change in (freight) volume to capacity ratios between the two years considered. In other words, if there are expected increases in freight volumes, but there are also roadway improvements (i.e., capacity expansions) planned, then the impact of these truck volume increases is minimized or even eliminated. On the other hand, if there is only increase in freight volume but not in roadway capacity, then the effect of heavy vehicles on traffic conditions and safety is more pronounced. Figure 15 and Figure 16 show these computations for the entire region and for the downtown/airport area, respectively. In the limit, if there are no roadway capacity improvements planned, Figure 14 and Figure 15 would be the same. 


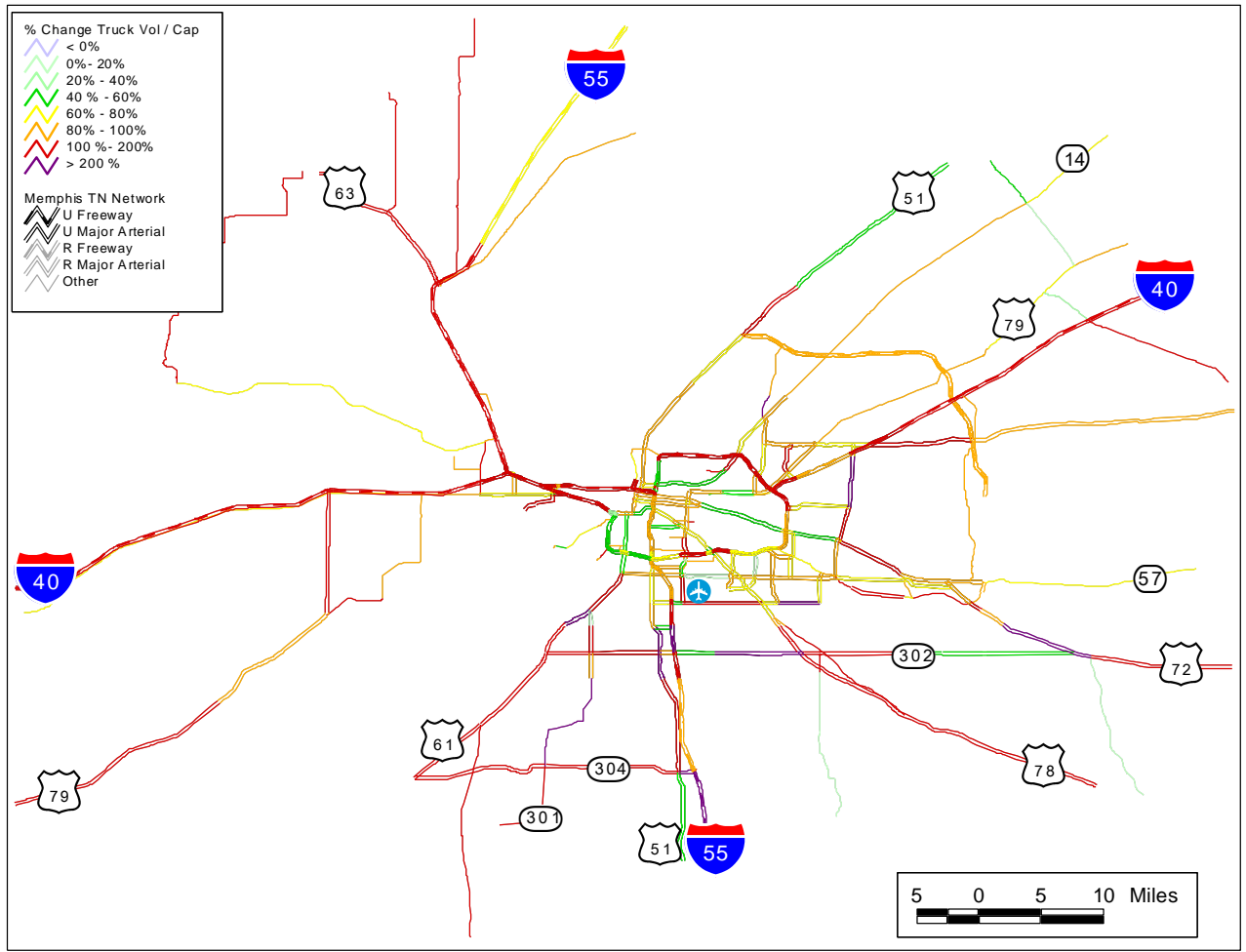

Figure 15 No-Build Alternative - Freight Volume / Capacity Change (Base to Forecast Year)

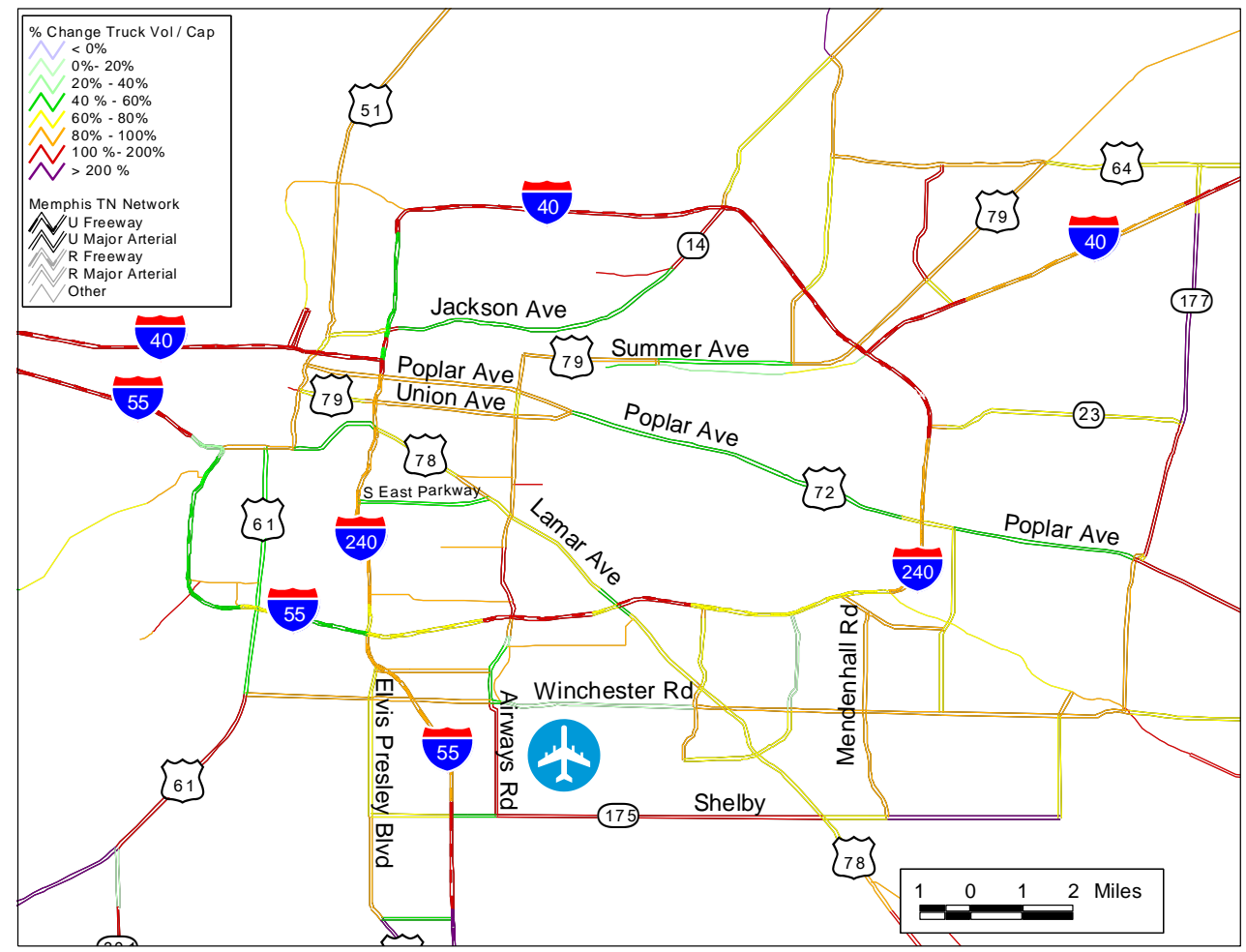

Figure 16 No-Build Alternative - Downtown and Airport Area Freight Volume / Capacity Change (Base to Forecast Year) 


\subsubsection{Freight Traffic Assignment}

At the local level, the construction of I-69 SIU-9 will only affect the redistribution of traffic in the Memphis area. That is, if isolated SIUs (i.e., SUI-9 or just a few segments upstream and downstream of this SUI) are built, then only the distribution of local traffic in the region will be affected. New alternative routes would be created by the construction/improvement of existing roadways with shorter travel times between a subset of origin-destination pairs in the area, thus inducing the re-routing of some of the traffic in the network. These localized network capacity improvements would not attract traffic from outside the area, either vehicular or freight.

However, when the entire I-69 corridor is completed, it is expected that there would be a redistribution of the freight flows at the national level. This will almost certainly result in increases in heavy truck volumes in the metropolitan areas (e.g., Memphis, in this case) that are traversed by the new facility. The EIS subject of the present study indicates that freight flows were obtained from the I-69 National Trade Corridor Study; however, no specific information is provided regarding through-freight trips on that corridor.

For this specific project (and for any other EIS that requires traffic investigations that can be affected by trough freight trips), FHWA and its consultants can update the national highway network to include the I-69 corridor (in its entirety, or even a few SUIs around the area) and rerun their commodity flow traffic assignment (with the current commodity O-D if it already includes Canada-USA-Mexico freight trips, or update the commodity O-D to reflect those trips) to provide through-freight trips information.

At the local level, the forecasted freight information included in FAF can be added to the regional travel demand model (after making adjustments to synchronize the FAF and EIS forecast years) and the demand model re-run to re-compute traffic flows, including the additional through-freight flows. However, to make this possible it is necessary to derive an O-D matrix from the information provided in FAF. Since the FAF O-D commodity matrix is not publicly available, it is not possible to simply extract a sub-matrix with the information that is relevant to the area being studied. Therefore, a different approach has to be implemented. This approach is discussed in the next subsection.

\subsection{Distribution and Assignment of Freight Traffic - Localized Traffic Network Improvement Projects}

In general, O-D information is obtained by conducting a survey such as, for example, the 2002 Commodity Flow Survey used in the FAF. Applying this method, however, is too costly and in relationship with the problem at hand, unfeasible. The challenge, then, is to obtain O-D traffic demand data without explicitly observing it. One way to address this challenge is to synthesize O-D data from known (e.g., recorded) roadway traffic flows. A considerable amount of research has been performed over the years in theoretical approaches to produce accurate synthetic O-D demands from such link flow counts. Based on this body of research, software has been developed to make operational these methods to synthetically estimate O-D matrices.

One such software package, Queens $O D$ [9], was used in this project to recover the O-D information from the FAF data for the Memphis, Tennessee region. Queens $O D$ estimates origin-destination traffic flows based on observed link traffic volumes, link travel times and, if 
available and applicable, observed link turning movement counts and other additional information (e.g., drivers' route choices) [10, 11].

Information about link traffic volumes for freight traffic, a requirement of the Queens $O D$ model, is available in the FAF database (see Table 1). The database also contains freight volumes for local trips (origin and destination in the Memphis area), as well as travel speeds for each link in the network. The latter, combined with link lengths extracted from the geo-database created for this project, permitted the calculation of link travel times, which is another requirement of the software.

The final requirement, the topology of the relevant transportation network, was also extracted from the project geo-database. Since the through freight traffic is assumed to travel on freeways, the selected sub-network consisted of all the highway segments in the area of interest, plus the interchanges with major arterials in the region. The latter were added to capture those freight trips that could have Memphis as origin or destination, but which have the other end of the trip at a location outside the area. Figure 17 shows the topology of the extracted network that was used with QueensOD. In this network, each link end that was not connected to another link was defined as an origin and destination zone (there were 38 O-D zones in total).

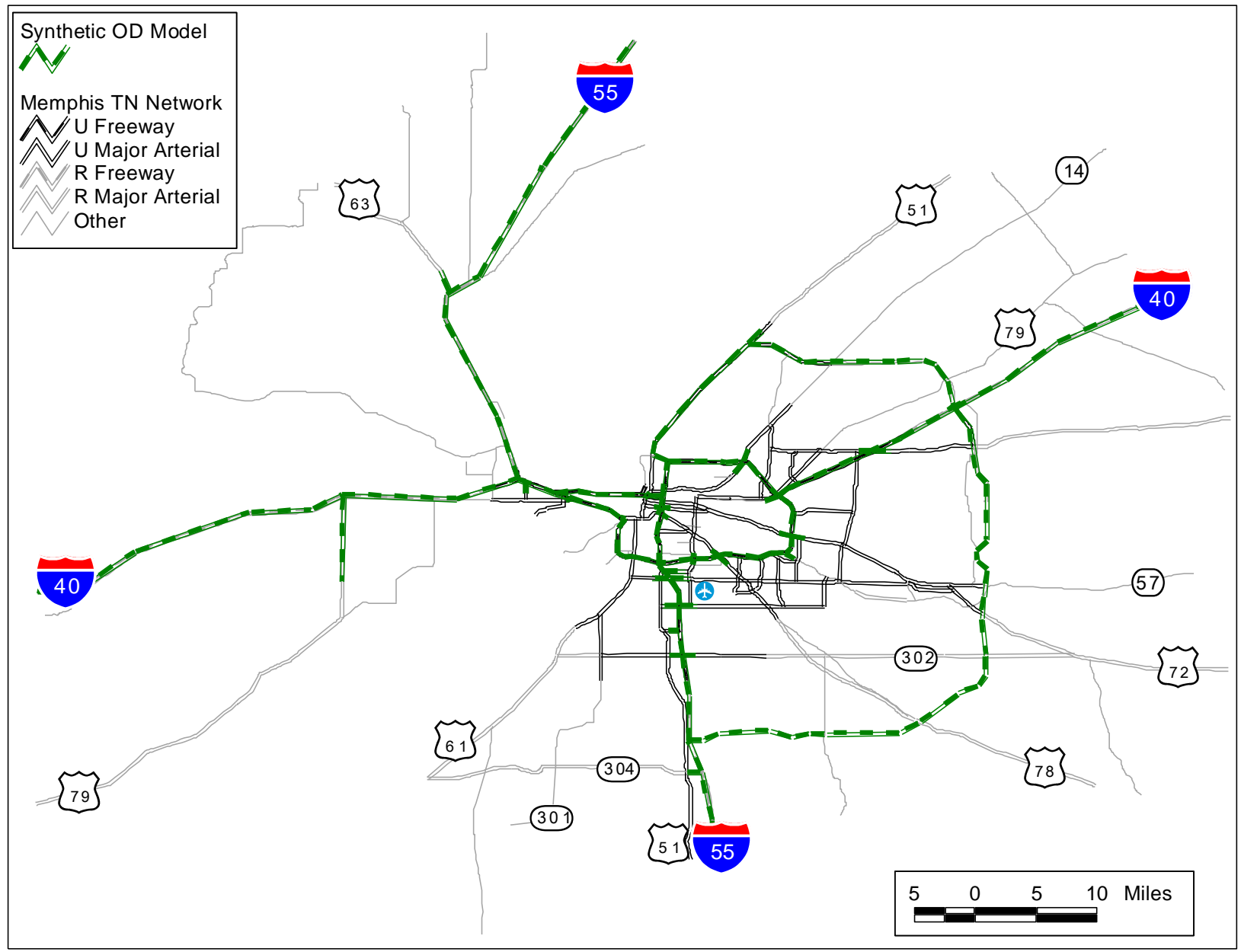

Figure 17 Synthetic O-D Network 
As an example of the methodology developed for the extraction of the freight O-D matrix from the FAF database and assignment of these flows to the Memphis 2030 network, consider the existing freeway system depicted in Figure $18^{3}$. For simplicity reasons consider only the through freight (i.e., both ends of the trip outside the Memphis region). In this case there are only 4 zones, corresponding to the four highway links that connect the area to the rest of the nation through the interstate highway system. Those zones were numbered 1 through 4 and are shown in Figure 18.

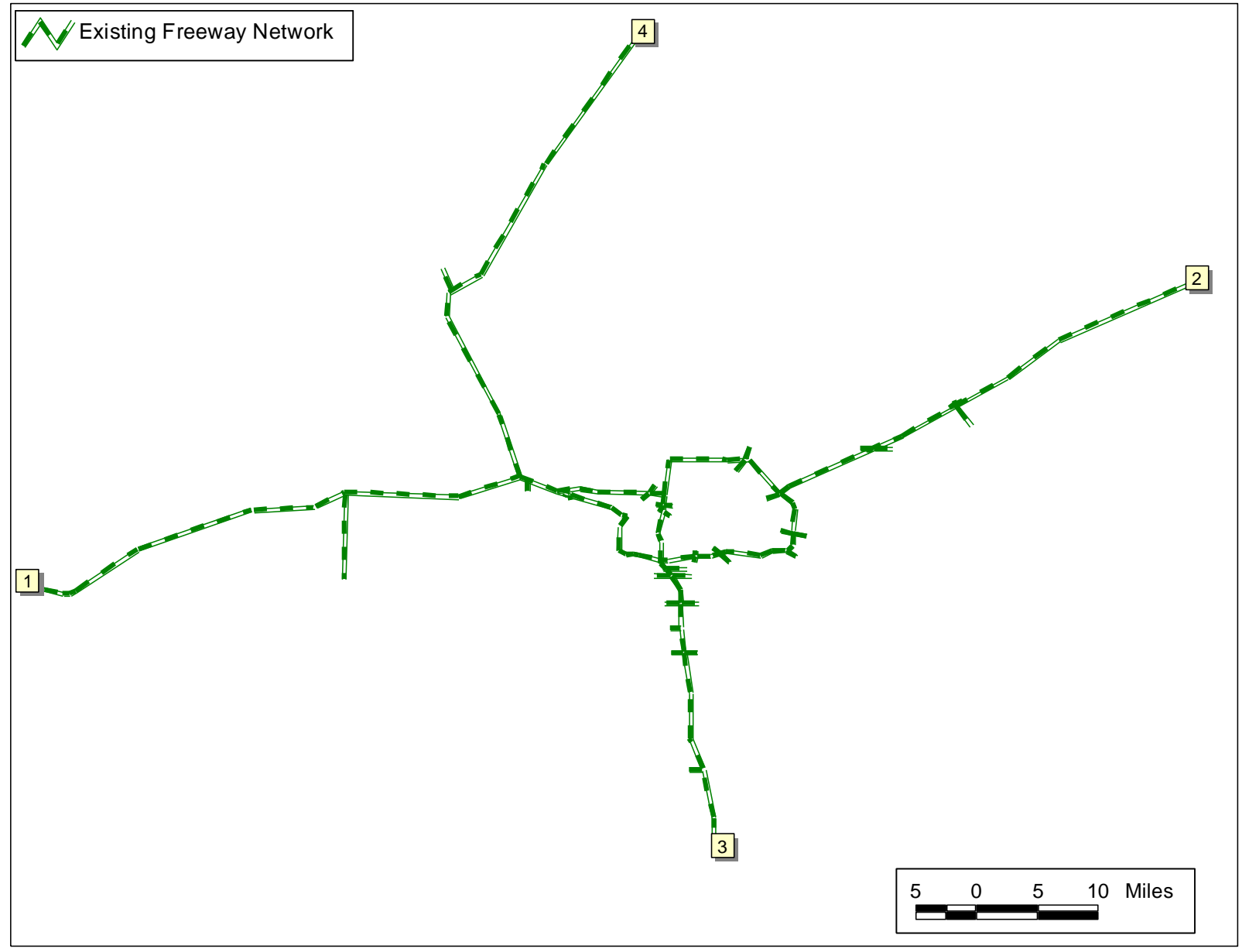

Figure 18 Synthetic O-D Network - Existing System

With the network information (topology), link travel times, and link truck flow based on the freight demand model and FAF 2.2 O-D database for the forecast year (see Table 1), the Queens $O D$ was run. The software then generated as output the synthetic O-D matrix presented in Table 1Table 2. Consider, for example, freight trips that enter the area through I-55 NB (zone 3 in Figure 18) and that are traveling eastbound exiting the area trough I-40 EB (zone 2). The results presented in Table 2 indicate that, on average (AADT), there are 1,607 such trips each day. (Notice that the heaviest through-freight flows are between zones 1-2 and 2-1, on I-40.)

\footnotetext{
${ }^{3}$ Figure 18 shows a representation of the freeway network in the Memphis area that was used in FAF (i.e., no I-269 was included in the database). Therefore, this network was the network adopted to extract the synthetic through-freight O-D matrix.
} 
Once the freight O-D has been generated, the next step is to assign these trips to the transportation network. For the forecast year, the Memphis area freeway network is expected to have I-269 completed. Therefore, the question is how many of these 1,607 heavy vehicle trips will take I-269 (i.e., following route 1: I-55 NB, I-269 NB, I-40 EB) and how many will travel through I-240 (i.e., following route 2: I-55 NB, I-240 EB, I-40 EB). This question is answered by using a traffic assignment model; which in this case would indicate that all the 1,607 trips will follow the route 1 (i.e., I-55 NB, I-269 NB, I-40 EB) ${ }^{4}$.

Table 2 - Freight O-D Matrix (Through Traffic)

\begin{tabular}{|c|c|c|c|c|c|}
\hline & \multicolumn{4}{|c|}{ Destination } \\
\hline & & 1 & 2 & 3 & 4 \\
\hline \multirow{4}{*}{$\frac{5}{5}$} & 1 & & 20,579 & 4,059 & 11,362 \\
\hline & 2 & 20,223 & & 1,218 & 2,964 \\
\hline & 3 & 4,100 & 1,607 & & 420 \\
\hline & 4 & 11,396 & 3,394 & 384 & \\
\hline
\end{tabular}

\section{BENEFITS OF THE PROPOSED APPROACH}

The traffic investigation is one of the most important tasks of any EIS, since the transportation/traffic impacts (both positive and negative) of the project being evaluated will directly affect all the population in the area, and for most of the public, these effects will be experienced on a daily basis. Therefore, it is important that travelers and decision makers have a clear picture of the traffic related outcomes of each alternative considered.

The utilization of CRS\&SI technologies can provide important benefits in this regard and reduce, or completely eliminate, the shortcomings that are associated with the current state of the practice of EIS traffic investigations. These technologies can bridge the gap of analysis and depiction of results. The integration of travel demand and other transportation/traffic models with CRS\&SI technologies allows easy expansion the traffic investigation analysis and results from the current LOS calculation to other transportation/traffic parameters (e.g., delays and volume-to-capacity ratios) that are more meaningful to laymen and non-transportation experts. Also, additional information (e.g., freight volumes) not generally included in the EIS, can be explicitly conveyed to facilitate a better decision making process.

With the assistance of CRS\&SI technologies, the results of these analyses can be expanded to all the roadways in the affected area and not be restricted (because of information delivery issues with the current state of the practice) to just the road segments directly affected. This is important since changes in any transportation facility will affect the entire network of a region. Hence, CRS\&SI technologies can help deliver a much better understanding of the (traffic conditions) impacts of the different alternatives not only in terms of the quality and relevance of the information, but also in terms of coverage.

\footnotetext{
${ }^{4}$ Although route 1 is longer than route 2 (45.2 miles vs. 43 miles) and it will take approximately 2 more minutes to travel it at free-flow speed (70 $\mathrm{mph}$ ), route 2 is much more congested as shown by Figure 11. Therefore, it will take a longer time under predicted traffic conditions to go from zone 3 to zone 2 using route 2 , which will make route 1 the selected route.
} 
The benefits that these technologies can bring in aiding in the decision-making process are substantial when compared with the current state of the practice. There are, however, some associated costs. The main one is, perhaps, related not to bottom line dollars, but to institutional barriers. In many cases, the travel demand models used in the analyses are stand alone models that have been reliably performing their task over many years. Therefore, there is an understandable reluctance to change these models/software utilities. However, as described above, there are many two-way interfaces with GIS platforms that have been developed for the most used travel demand models which can help in this regard by making these connections transparent to the transportation analyst. The other option, switching to the new models that have integrated GIS capabilities, has a material cost associated with the software itself, and in some cases with the training of the technical personnel that runs these models. The latter could be important, especially if the transition is to a different model that is currently been used. But these software utilities also bring many new capabilities that can be used in many other projects besides EISs.

Regarding the costs of the additional results, those are minimal since the LOS computations (i.e., the current state of the practice) already involve in the calculations some of these parameters. In relationship to freight information, and especially regarding through freight, it should be provided by FHWA since this agency maintains a national database (including O-D and other relevant information) about the movement of freight in the US. There may be a cost associated with this for FHWA, but the benefits of including heavy truck information in the evaluation of the different alternatives in an EIS are very important as discussed in this report. 


\section{REFERENCES}

1. Highway Capacity Manual (HCM2000), Transportation Research Board, Washington, DC, 2004.

2. Interstate 69, Section of Independent Utility \#9 - Final Environmental Impact Statement. Federal Highway Administration, FHWA-TN-EIS-04-01F, 2006.

3. Thomas W. and T. Hoffman, Geographic Information in Travel Demand Model Network Development, in Proceedings of the Seventeenth Annual ESRI User Conference, 1997, San Diego, CA.

4. Nguyen-Luong, D., Interface between ArcInfo and MinUTP, in Proceedings of the 1996 ESRI European User Conference ESRI (UK), London, England, October 1996.

5. Matzzie D. E. and R. H. Rogers, GIS in Transportation Modeling: Merging MinUTP with GIS, in Proceedings of the Civil Engineering Applications of Remote Sensing and Geographic Information Systems Conference, Washington, DC, May 14-16, 1991.

6. Li, N, X. Zou, and D. Levinson (2004) Sharing Data between Arc/Info and EMME/2: Practice in Lyon County, Minnesota. Presented at 45th Transportation Research Forum Annual Meeting, Evanston, Illinois, March 21-23, 2004

7. EMME - Equilibre Multimodal / Multimodal Equilibrium; http://www.inro.ca

8. FHWA Office of Freight Management Operations, US Department of Transportation; http://ops.fhwa.dot.gov/freight/index.cfm

9. M. Van Aerde \& Assoc., (2005), QUEENSOD Rel. 2.10 - User's Guide: Estimating Origin - Destination Traffic Demands from Link Flow Counts, M. Aerde and Associates, Ltd., Blacksburg, Virginia. < PDF Draft >

10. Rakha H ., Paramahamsan H., and Van Aerde M. (2005), Comparison of Static Maximum Likelihood Origin-Destination Formulations. Transportation and Traffic Theory: Flow, Dynamics and Human Interaction, Proceedings of the 16th International Symposium on Transportation and Traffic Theory (ISTTT16), pp. 693-716.

11. Van Aerde M., Rakha H ., and Paramahamsan H. (2003), Estimation of $O-D$ Matrices: The Relationship between Practical and Theoretical Considerations. Transportation Research Record, No. 1831, pp. 122-130. 